\title{
CEsifo \\ WORKING

\section{The Elusive Quest for the Holy Grail of an Impact of EU Funds on Regional Growth}

Jan Fidrmuc, Martin Hulényi, Olga Zajkowska 


\section{Impressum:}

CESifo Working Papers

ISSN 2364-1428 (electronic version)

Publisher and distributor: Munich Society for the Promotion of Economic Research - CESifo

$\mathrm{GmbH}$

The international platform of Ludwigs-Maximilians University's Center for Economic Studies and the ifo Institute

Poschingerstr. 5, 81679 Munich, Germany

Telephone +49 (0)89 2180-2740, Telefax +49 (0)89 2180-17845, email office@cesifo.de

Editor: Clemens Fuest

www.cesifo-group.org/wp

An electronic version of the paper may be downloaded

- from the SSRN website: www.SSRN.com

- from the RePEc website: www.RePEc.org

- from the CESifo website: www.CESifo-group.org/wp 


\title{
The Elusive Quest for the Holy Grail of an Impact of EU Funds on Regional Growth
}

\begin{abstract}
We analyze the impact of EU structural and cohesion funds on economic growth of European regions, using 2SLS to tackle the potential problem of endogeneity, and estimating a spatial model to account for inter-regional spillovers. We use the presence of environmentally protected areas (under the European Union's Natura 2000 program) as instruments for the receipts of funds from the EU Cohesion Policy. We find that the European funds have a significant and positive effect on regional economic growth in the EU. The inter-regional spillovers in the effect of Cohesion Policy on regional growth are found to be important: most of the effect takes place outside of the recipient region rather than inside. However, there is considerable heterogeneity in the effect of Cohesion Policy across individual EU member states: the effect is stronger in the new member states, and weak or negative in the countries hit by the recent austerity measures. Finally, our results confirm the positive impact of institutional quality: improvements in economic development across the EU do not necessarily require only redistribution: institutional reform can also help boost growth performance.
\end{abstract}

JEL-Codes: C210, C360, F360, E620, O110, P480.

Keywords: regional aid, growth, environmental conservation, 2SLS, spatial model.

Jan Fidrmuc*
Department of Economics and Finance
Brunel University
United Kingdom - UB8 3PH, Uxbridge
Jan.Fidrmuc@brunel.ac.uk

Martin Hulényi

Institute for Strategy and Analysis (ISA)

Government Office of the Slovak Republic

Bratislava / Slovakia

martin.hulenyi@vlada.gov.sk
Olga Zajkowska

Institute of Economics and Finance

Warsaw University of Life Sciences

Warsaw / Poland

olga_zajkowska@sggw.pl 
December 2, 2019

This research was initiated while Olga Zajkowska was visiting the Analytical Unit at the Government Office of the Slovak Republic, whose hospitality and financial support she gratefully acknowledges. We received helpful comments and suggestions from Julia Bachtrögler, Peter Huber, Mikuláš Luptáčik, Aleksander Łaszek, Katarína Rimegová, Vicente Rios, Alena Sabelová; seminar participants at Brunel University, Narodowy Bank Polski, Slovenská Národná Banka, University of Economics in Bratislava and Kazakh-British Technical University; and conference attendees at European Public Choice Society, Royal Economics Society, Slovak Economics Association, Warsaw International Economic Meeting, European Workshop for Political Macroeconomics, the "Economic prospects for the European Union: Challenges for economic policy until the end of the decade" conference in Düsseldorf, Germany, and the Trexima conference 25 years of transforming centrally planned economies in Bratislava, Germany. The views expressed in this paper are those of the authors and do not necessarily represent the official position of the Government Office of the Slovak Republic. 


\section{Introduction}

One of the key principles of the European integration process has always been solidarity. This is manifested, most prominently, in the funding set aside to support economic convergence within the European Union. Cohesion Policy, the primary tool of regional policy in the EU's toolbox, accounts for approximately one third of its budget. ${ }^{1}$ The importance of regional aid, furthermore, has been increasing over time: from less than $10 \%$ of the EU budget in the 1970s and the early 1980s to $32.5 \%$ in the $2014-20$ budget. This reflects the changing priorities in the wake of the European Union's expansions. The six founding members were at similar levels of economic development, so that there was little perceived need for regional aid. Rather, on the backdrop of food shortages during WWII, the bulk of the EU spending was dedicated to supporting agriculture to boost security of food supply. The accession of Greece in 1981, followed by Spain and Portugal in 1986, however, brought about considerable income differentials among member states and their regions. These differentials became even more prominent after the German Reunification in 1990 and the Eastern enlargements in 2004, 2007 and 2013. Correspondingly, the relative importance of regional aid has increased and the Cohesion budget has almost caught up with the funding earmarked for the Common Agricultural Policy.

According to economic theory, Cohesion Policy should have an unambiguously positive effect on growth. In this, inter-regional redistribution differs from conventional government spending. If consumers are forward looking, they factor in the future tax liability associated with current government spending (Barro, 1974, 1979). As a result, increased government expenditure at present should induce them to save rather than consume more, thus having little effect on current output. This argument, however, has little relevance for cross-border fiscal transfers such as the EU regional aid: the future tax liability associated with such transfers will be borne by tax payers in the EU as a whole, so that each region (or country) will only be responsible for a small fraction of the future tax liability associated with the regional aid that it receives. Therefore, the consumers in the recipient region have limited incentive to save (beyond smoothing consumption over the consumers' lifetime). Instead, they should see the increased spending as an increase in their permanent income and should adjust their consumption accordingly.

The evidence on the growth-boosting effect of EU regional aid, however, has been elusive so far. Some studies do find that Cohesion Policy has had a positive impact on economic growth. Other analyses, however, yield insignificant or even a negative effects. Broad overview studies by Dall'erba and Fang (2017) and Marzinotto (2012) observe a general lack of consensus in the literature over the sign of the effect of regional aid on growth. Dall'erba and Fang (2017) report that the average value in their sample of 323 estimates sourced from 17 studies is 0.174 (ranging from -7.6 to 6.3). In this, the Cohesion Policy literature mirrors the findings on the effectiveness of development aid (Doucouliagos and Paldam, 2009). Given the considerable amounts of money that the EU spends on Cohesion Policy and the rather optimistic prediction of economic theory, it is disappointing that clear and overwhelming evidence of a positive effect remains eludes the researchers.

Nevertheless, the absence of evidence of a positive effect does not necessarily confirm that no such positive effect exists. The positive effect could elude the researchers for a number of reasons, such as measurement errors in data on growth or Cohesion Policy transfers.

\footnotetext{
${ }^{1}$ We use the terms Cohesion Policy and regional aid interchangeably throughout the paper.
} 
It is also possible that the effects of regional aid are not limited to the recipient region but spill over to other regions. European regions are closely integrated into their national economies as well as to the EU-wide economy. Therefore, an investment located in any particular region can be executed by firms from other regions of the same country or from another EU country. Given that most analyses of economic effects of Cohesion Policy are executed at the level of regions, not accounting for such spillovers would serve to diminish the estimated effect.

An especially compelling explanation is the possibility that the relationship between regional aid and regional growth suffers from an endogeneity bias. For example, this could be because of the institutional set-up of regional aid in the EU whereby relatively poor regions get preferential access to Cohesion Policy funds. This could result in a negative correlation between regional aid and regional growth: fast-growing regions lose eligibility for European funds while slow-growing regions retain it. Empirically, this would lead to a downward bias when estimating the relationship between regional aid and regional economic growth. Another possibility relates to the process of conditional convergence at regional level: poor regions generally grow faster than those that are well off (Mankiw et al., 1992; Quah, 1996). However, since poor regions remain eligible for regional aid longer, this can generate spurious positive correlation between Cohesion Policy transfers and growth. In this case, the regression coefficients estimated by OLS would be biased upwards. Yet another possible reason for endogeneity can be omitted variables. For example, poor regions could be stricken by structural issues (such as unfavorable industrial structure or socio-economic characteristics) which depress their growth performance. Such regions report disappointing growth figures, despite relatively high receipts of European funds. In this case, the regression estimates would be biased again downwards.

Most previous studies ignore the possibility of the regional-aid effect being endogenous. If the bias due to endogeneity is downwards, this could explain the lack of positive estimates in many studies. Becker et al. (2010, 2018), Pellegrini et al. (2013) and Cerqua and Pellegrini (2018) attempt to remove the endogeneity bias by using regression discontinuity design. They utilize the fact that eligibility for Cohesion Policy changes once a region passes two arbitrary thresholds: $75 \%$ of the EU-average GDP per capita to be classified as less developed region and $90 \%$ for transition regions. Regions that are close to the threshold should be arguably very similar to each other economically, regardless of which side of the threshold they happen to be on. Their elibility for regional aid, however, changes when they exceed the threshold. Becker et al. (2010, 2018) and Pellegrini et al. (2013) find positive effects of regional aid on regional economic growth (although not on employment growth).

In our paper, we contribute to the quest to correctly identify the effect of Cohesion Policy on regional economic growth by addressing two of the aforementioned potential explanations: (1) endogeneity and (2) regional spillovers.

To deal with endogeneity satisfactorily, we require an instrument that is valid and strong: it needs to be closely correlated with the transfers that regions receive under Cohesion Policy, but it needs to be uncorrelated with the error term in the growth equation. We use the presence of environmentally protected areas (designated as such under the EU's Natura 2000 program) in EU NUTS 2 regions as an instrument for regional aid. The Natura 2000 scheme has awarded protection to over 27 thousand terrestrial and marine conservation areas, covering some $18 \%$ of the EU's land area and $6 \%$ of its sea surface. 
This makes the Natura 2000 the largest network of protected sites in the world. ${ }^{2}$ As we show below, the presence of protected areas and their relative size are strong predictors of the amount of funding that regions receives from Cohesion Policy. There are (at least) two plausible reasons for this. First, the presence of environmentally protected sites limits the nature and scope of industrial activity and infrastructure building in the region. In this context, is is important to note that most Natura 2000 areas are used for human habitation and/or economic activities, some intensively, including farmland and urban areas. Only around $13 \%$ of the protected areas can be classified as wild. However, because of their protected status, the human habitation and economic activity within the site have to be environmentally sustainable and are subject to restrictions. This means that some activities may not be allowed at all: for example, industrial or agricultural production resulting in excessive pollution or noise. Others may be different in nature from similar activities taking place in areas without environmental protection. For example, a new road through a protected area may have to be built according to more demanding specifications (such as adopting noise-reducing measures or having additional features to allow safe and unhindered access to a nesting/foraging site of a protected species) or it may have to be planned differently (such as going around the nesting site instead of taking the shortest possible route). These additional requirements are likely to make the investments in protected areas more expensive. Second, the regions hosting protected sites are likely to have better access to Cohesion Policy funding. The Natura 2000 network provides some direct funding but this is limited in nature. Gantioler et al. (2014) estimate that the annual funds available to finance Natura 2000 sites are just under $€ 6$ million. More importantly, Gantioler et al. (2014) stress that the regions with Natura 2000 sites can take advantage of funding opportunities from the European structural and investment funds and other financial instruments of the EU Cohesion Policy.

To capture the potential spatial spillover effects of Cohesion Policy, we estimate a Spatial Durbin Model (SDM). This allows for any explanatory variable to affect not only the outcomes of interest in the given region, but also in other regions, with the intensity of the spillover decaying with distance.

How much bang does the EU get for its Cohesion-Policy buck? In the next section, we briefly discuss the existing literature on the impact of Cohesion Policy on regional development. ${ }^{3}$ The data we use are described in section 3. Our empirical approach, in turn, is covered by section 4 . Besides addressing the endogeneity of Cohesion Policy, we also allow for their effect being heterogeneous across (groups of) countries, and estimate a spatial model that allow for inter-regional spillovers of regional aid. Section 5 then presents our results. We summarize our findings and put them into broader context in the last section.

\section{The Quest So Far}

The existing literature on the effect of structural funds on economic growth paints a rather mixed picture so far. Some studies find a positive impact of structural funds on economic growth (Beugelsdijk and Eijffinger, 2005; Bradley et al., 2004; Bradley and Untiedt, 2007; Maynou et al., 2014; Radvansky et al., 2015; Rodriguez-Pose and Fratesi, 2004; Cappelen

\footnotetext{
2 See "Natura 2000," European Commission, http://ec.europa.eu/environment/nature/natura2000/ index_en.htm, accesssed July 2019.

${ }^{3}$ For more extensive discussion, see Dall'Erba and Le Gallo (2008) and Pellegrini et al. (2013).
} 
et al., 2003; Venables and Gasiorek, 1999; Cerqua and Pellegrini, 2018). Others conclude that the effect is either insignificant or even negative (Boldrin et al., 2001; Fagerberg and Verspagen, 1996; Dall'Erba and Le Gallo, 2008; Eggert et al., 2007). The meta-analysis by Dall'erba and Fang (2017) reviewes the quantitative evidence in 17 studies which together yield 323 estimates of growth elasticities. The average estimate is close to zero at 0.174 and the range of estimates is high: from -7.6 to 6.3. Marzinotto (2012) confirms this by calling the literature inconclusive and pointing out that actual empirical tests tend to produce worse results than macroeconomic simulations.

Some studies find a conditional effect of EU funds but not a direct one: the impact of regional aid is positive only in the presence of sound institutions (Rodríguez-Pose and Garcilazo, 2015), when the stock of human capital is high and the government is decentralized (Bähr, 2008), or the funds are managed efficiently (Wostner and Šlander, 2009). Another set of studies find positive effects only in specific sectors of the economy (Rodriguez-Pose and Fratesi, 2004), for specific funding objectives (Mohl et al., 2008), or only at some levels of analysis (Le Gallo et al., 2011).

The research regarding the impact of regional aid on employment is similarly inconclusive. Dall'Erba et al. (2007) fail to find any positive effects, Mohl and Hagen (2010) find only a modest effect, while Bradley et al. (2004) and Radvansky et al. (2015) suggest that the effect is significant and positive.

The reasons for the heterogeneity of findings, and the lack of positive effect, are several: the studies use different data sets, apply different analytical methodologies, and are based on different periods. A recent meta-analysis by Dall'erba and Fang (2017) observes that the later the research was conducted, the higher was the estimated impact of the EU funds. They attribute this finding to the learning effect on the side of the member states: countries learn over time how to implement the funds more effectively. They also suggest that there may be similar learning effect on the side of the researchers themselves, whose methodological approaches improve over time. Marzinotto (2012), in turn, suggest that the disappointing and inconclusive evidence may imply that Cohesion Policy transfers are allocated inefficiently, managed badly, or used for investment projects that contribute little to growth.

Another possible explanation for the lack evidence of a growth-boosting effect of European redistribution is the possibility that the estimated relationship is marred by endogeneity. Dall'erba and Fang (2017) recognize this, and note that most of the literature ignores this problem. The main exceptions are Becker et al. (2010, 2018), Pellegrini et al. (2013) and Cerqua and Pellegrini (2018) who follow a quasi-experimental approach. They take advantage of the fact that the bulk of regional aid is distributed according to the so-called Convergence Objective (previously known as Objective 1). Under this objective, a large share of Cohesion funds is set aside for regions whose GDP per capita is below $75 \%$ of the EU average. ${ }^{4}$ Once a region surpasses this threshold, the amount of funds that it is eligible to receive shrinks considerably. Arguably, regions that are just below and just above this threshold should be very similar to each other in every respect other than their ability to draw regional-aid funds. Becker et al. (2010, 2018), Pellegrini et al. (2013) and Cerqua and Pellegrini (2018) use the regression discontinuity design (RDD) to test whether regions on

\footnotetext{
${ }^{4}$ The EU categorizes its regions into less developed, transition and more developed, defined as having GDP per capita below $75 \%$, between $75 \%$ and $90 \%$, and above $90 \%$ of the EU average, respectively. The bulk of funding, for example, just over $50 \%$ in the $2014-2020$ programming period, goes to the less developed regions.
} 
either side of the threshold fare differently with respect to their growth performance. They find that being eligible for Convergence Objective funding is associated with significantly better growth performance but not with better employment outcomes.

The downside of the RDA approach is that the treatment is measured by means of a dummy variable: a region is either below or above the Convergence Objective threshold. Therefore, it is not possible to account for the intensity of the treatment (the extent of funding received). Another disadvantage is the fact that in several instances the regions' eligibility status deviates from the formal rule: some regions are found to be eligible for funding under the Convergence Objective even though their GDP per capital exceeds the threshold, while other regions that are below the threshold are not eligible. Becker et al. (2010) resolve this by applying a fuzzy RDA; Pellegrini et al. (2013) drop such regions. A final issue refers to the fact that analysis based on the Convergence Objective disregards Cohesion Policy funding under other objectives: some 50\% of regional aid is set aside for less-developed regions, so that another half is available for investments in regions that do not meet the Convergence Objective.

Dall'Erba and Le Gallo (2008) follow a different approach: they use generalized spatial 2SLS (GS2SLS), choosing geographical distance and travel time to Brussels as instrumental variables. The benefit of this approach is that it captures the presence of spatial spillovers between geographically close regions. However, as these instruments are constant over time, they can be used only in a cross-section analysis; such instruments cannot be utilized in panel data analysis such as ours. Dall'Erba and Le Gallo (2008) conclude that the process of convergence among European regions is ongoing, but EU Funds do not play much role in it. Inter-regional spillovers are important only in the core regions of the EU, whereas they more limited in peripheral areas.

With our analysis, we seek to contribute further to the quest to determine if the effect of Cohesion Policy on growth is positive. To aid us in this quest, we select an instrument that is neither time-invariant nor dependent on how the regions' measure up relative to the EU average per-capita GDP: the presence of environmentally protected areas in each region.

\section{Data}

Given the nature of our analysis, we have to combine data from a number of different sources. First, we use the annual receipts of EU funds at the level of NUTS 2 regions as reported by the European Commission. ${ }^{5}$ Until recently, only the total payments over whole programming periods were available at the NUTS 2 level. To the best of our knowledge, ours is one of the first papers that uses these newly available annual data for an economic analysis of the Cohesion Policy impact. ${ }^{6}$ Only data covering the Cohesion Policy payments during the last three programming periods, 1994-1999, 2000-2006 and 2007-2013, have been

\footnotetext{
${ }^{5}$ See https://cohesiondata.ec.europa.eu/EU-Level/Historic-EU-payments-regionalised-and-modelled/ tc55-7ysv.

6 This was a constraint for previous analyses, which either had to work with programming-period averages, or had to intrapolate and/or estimate the annual figures. For example, Roemisch (2017) used country-level annual data at project level to create estimates of regional-level annual data, since project names often contained information about the recipient region.
} 
made available in annual frequency so far, which determines our choice of time period. ${ }^{7}$ Funds allocated to a region in any given year have to be spent during that year and/or the next two (occasionally three) years. Our data record the annual disbursements (rather than allocations) of Cohesion Policy funds. Because of this, some of the funds allocated during the last 2-3 years of the 2007-2013 programming period were only disbursed during 2014 to 2016. We keep the information for 2014 (when most of the spending is likely to be funds allocated during the preceding programming period, but drop 2015 and 2016 from our analysis. ${ }^{8}$ Finally, we use only the total amounts of regional aid received by each region, without breaking it down further by categories of spending. ${ }^{9}$

The regional distribution of the EU funds for 1997, 2004 and 2013 is depicted in Figure 1 . The maps clearly show how the geographical focus of Cohesion spending has shifted over time. Traditionally, Cohesion Policy mainly benefited regions at the periphery of the EU15: Southern Europe, East Germany, Northern Britain, and Ireland. After the Eastern enlargements in 2004 and 2007, the bulk of funding was redirected towards the new member states in Eastern and South-Eastern Europe. ${ }^{10}$

We complement the Cohesion Policy data with regional economic statistics, provided by Cambridge Econometrics' European Regional Database. We use also the Worldwide Governance Indicators compiled by Kaufmann et al. (2011). These cover six areas: Voice and Accountability, Political Stability and Lack of Violence, Government Effectiveness, Regulatory Quality, Rule of Law, and Control of Corruption. We collapse them into a single composite indicator by means of principal component analysis. The governance indicators are available from 1996 until 2016 at the country level only. ${ }^{11}$ Furthermore, they are available in yearly frequency only since 2002. Therefore, we impute the missing years using a Monte Carlo simulation of the regression of the composite index on a polynomial of time.

Finally, to construct our instrument, we use the information on the location and size of Natura 2000 areas, made available by the European Commission. ${ }^{12}$ The precise geographical coordinates of all Natura 2000 sites were required to allocate the sites to NUTS 2 regions and also to compute the area of each site. The source of the coordinates is the European Environmental Agency(EEA). ${ }^{13}$ Based on the geospatial data from the EEA ${ }^{14}$ and Eurostat,${ }^{15}$ we attribute each site (excluding marine areas) to a NUTS2 region based on

\footnotetext{
${ }^{7}$ Cerqua and Pellegrini (2018) also use the new yearly data. However, they restrict their analysis to the regions of the EU15 and 1994-2006 period.

${ }^{8}$ In principle, the same issue applies to the end of each programming period. However, for the 1994-1999 and 2000-2006 budgets, the end-of-budget spending overlaps with spending allocated during the first 2-3 years of the next period, which also appears in our data. It is only the beginning-of-budget spending in the 2014-2020 programming period that our data set misses.

${ }^{9}$ Only information on spending by the various EU funds (European Regional Development Fund, Cohesion Fund, European Social Fund, and European Agricultural Fund for Rural Development) is available in annual frequency. Breakdown by sectors is available for whole programming periods only.

10 The new member states were ineligible for EU regional aid before joining the EU. We therefore assign them zero disbursements of Cohesion Policy funds in the pre-accession years. The candidates for EU membership did receive some fiscal support from the EU already before their EU accession, but the scale of this support was dwarfed by the amounts that they received following their EU accession.

11 Teorell et al. (2018) provide data on the quality of institutions at the NUTS 2 level, however, their data cover only three years: 2010, 2013 and 2017.

12 See https://ec.europa.eu/environment/nature/natura2000/data/index_en.htm.

13 See http://www.eea.europa.eu/data-and-maps/data/natura-1 and http://bd.eionet.europa.eu/ activities/Natura_2000.

${ }^{14}$ See http://www.eea.europa.eu/data-and-maps/data/biogeographical-regions-europe-3.

${ }^{15}$ See https://ec.europa.eu/eurostat/web/gisco/geodata.
} 
the coordinates of the centroid of the Natura sites. In some cases, the centroid of a Natura site lies in a different region because of the shape of the site and the location of regional borders. ${ }^{16}$ For that reason, we also web-scrape the publicly available application forms of the Natura sites and correct the mistakes that arise from the spatial assignment of the sites. Lastly, we collapse the individual data on sites into regional aggregates, yielding the proportion of each NUTS 2 region's area that is protected by the Natura 2000 network, as well as the number of environmentally protected sites per regions, which constitute our instruments.

Figure 2 depicts the proportion of the area of Natura sites to the total area of each region in 1997, 2004 and 2014. Note that the ratio was very low in most EU regions in 1997. This is because the Natura 2000 program was established only in 1992. Since then, we can observe that the ratio has increased markedly in the Mediterranean countries (especially Spain, Greece, France) and the new member states (most notably Bulgaria, Romania, Slovakia, Poland). The regions with a high density of Natura 2000 sites also tend to have a high ratio of EU funds to GDP: the correlation between the Natura 2000 site proportion and the ratio of regional aid to GDP is around 0.33. On the other hand, the correlation between Natura 2000 sites and the growth of output per capita is substantially lower at -0.10 . This suggests that our instrument is closely linked with our endogenous variable but is not correlated with the dependent variable.

We thus have data from 1994 until 2014 at the NUTS 2 level: altogether 272 regions (in their 2013 definitions). An overview of the main variables is provided in Table 1, while Table 2 displays the descriptive statistics. Finally, Figure 3 reports the correlations between the various variables.

\section{Methodology}

We estimate an augmented version of the standard Solow-Swan growth model at the regional level with yearly data (Mankiw et al., 1992; Islam, 1995). Specifically, we estimate

$$
\begin{aligned}
\Delta \ln y_{i j t}= & \beta_{0}+\beta_{1} \ln y_{i j t-1}+\beta_{2} \ln s_{i j t}+\beta_{3} \ln \left(g_{i j t}+n_{i j t}+\delta_{i j t}\right)+\beta_{4} \text { wgipca }_{i t} \\
& +\gamma_{1} \ln \text { eufr } r_{i j t}+\gamma_{2} \ln \text { eufr } r_{i j t} * E U 10+\gamma_{3} \text { lneufr }_{i j t} * E U 3+\gamma_{4} \text { lneufr }_{i j t} * \text { GIPS } \\
& +\mu_{j}+\tau_{t}+u_{i j t} .
\end{aligned}
$$

The dependent variable is the log-difference of per-capita output of region $j$ located in country $i$ in time $t$. The first line contains the standard elements of the Solow model: the lagged output per capita ( $y$ measured in the preceding year), ratio of gross fixed capital formation to GDP $(s)$, population growth ( $n$; note that $g$ and $\delta$ stand for the rates of technological progress and depreciation, respectively). To this, we add the weighted average of the World Governance Indicators (wgipca, with the weights determined by principal component analysis). We follow the practice common in the literature and replace the sum of technological progress and depreciation rate with a constant term equal to $0.06 .{ }^{17}$

\footnotetext{
${ }^{16}$ For example, some Natura 2000 sites are constituted by rivers or river banks. If the river happens to be the border of a region, and is concave, then the centroid of the site would be located in an adjacent region.

17 Mankiw et al. (1992) use 0.05 as the sum of technological progress and depreciation. Using 0.05 would result in the loss of two observations, Thessaly in Greece in 2000 and Nord-Est in Romania in 2012, which recorded negative population growth rate of $5 \%$.
} 
The second line contains our variable of interest: the ratio of the EU funds to GDP (efpayr). Since some regions receive no regional aid in some years, we add 1 to this ratio before taking logs. In the baseline specification, we estimate the average regional aid effect for all member states. However, we also estimate an alternative specification that allows the EU funds to have different effects on growth in specific groups of countries: EU10 - the new member states that joined the EU in 2004, EU3 - the next three entrants, Bulgaria, Romania (both joined in 2007) and Croatia (EU member since 2013), and GIPS - Greece, Ireland, Portugal and Spain, the countries affected by the European debt crisis since 2009. We can think of a number of of reasons why the EU funds could have different effects groups of member states. The new member states may lack the experience and expertise required to prepare effective projects that could benefit from EU funding. On the other hand, Ireland and Southern European member states were on the receiving end of EU funds for a few decades now. It is therefore possible that they might display diminishing returns to EU funding, whereby most projects with high rate of return have already been funded. Furthermore, the austerity measures implemented in the wake of the European debt crisis are likely affect the return on EU investments in these countries. The new member states and the traditional recipients of regional aid may also encounter problems due to limited absorption capacity, and/or because the amount of funding exceeds the growth-maximizing level (Becker et al., 2012).

Finally, we also include fixed effects for regions, $\mu_{j}$, and time, $\tau_{t}$. All observations pertain to country $i$, NUTS 2 region $j$ and year $t$, with the exception of the governance indicators, which are measured at the national rather than regional level.

Using the regression estimates of equation (1), we can calculate the convergence rate, $\lambda$ :

$$
\lambda=-\frac{\ln \left(1+\beta_{1}\right)}{t}
$$

This is the speed, at which the average NUTS 2 region approaches its steady state. Alternatively, $\frac{\ln (2)}{\lambda}$ is the half-life of convergence: the amount of time required, on average, for a region to halve the distance that separates it from its steady state (Arbia, 2006).

To address the endogeneity of EU funds, we use the presence of Natura 2000 sites in each region. We construct two measures of the presence of Natura 2000 sites. Our preferred instrument is the proportion of the region's area that is taken up by Natura 2000 sites. In some specifications, we also add the number of Natura 2000 sites per region as an additional instrument. We believe that the proportion better reflects the extent of environmental protection than a simple count of sites: some sites (national parks) are very large, while others (man-made structures such as buildings, towers and mines, which serve as nesting sites) can be very small. Nevertheless, both instruments are strongly and positively correlated with the amount of regional aid disbursed to European regions, both when we enter them in the first-stage regression one at a time or jointly (see the next section for more details).

The EU constitutes a single free market for goods and services with unhindered mobility of labor and capital. Therefore, the effects of regional aid are unlikely to be confined to the recipient region. Rather, we should expect the funds spent to translate into an increase in aggregate demand in the recipient region as well as in (especially nearby) regions in the same country or in other countries. This requires the use of a spatial weight matrix, which determines how each region is affected by other regions. The choice of weights is somewhat arbitrary and mainly depends on the assumptions made in the model. In our case, since 
several NUTS 2 regions are islands, we opt for using a spatial weight matrix based on distance rather than contiguity. Specifically, we use $d_{i j}$, the great-circle distance between the centroids of regions $i$ and $j$, in kilometers. ${ }^{18}$ As Kopczewska et al. (2017) note, the squared inverse distance matrix captures both the global links between all units and local clusters, as the strength of the relationship between regions declines exponentially with distance. Since far-away regions are unlikely to exert much influence (and given that we use the inverse square distance, their weight would approach 0 ), we only consider spillovers from regions located within a threshold distance (as explained below) from the recipient region.

Thus, the spatial weight matrix $\mathbf{W}$ has the following form:

$$
w_{i j}= \begin{cases}0 & \text { if } i=j \\ \frac{d_{i j}^{-2}}{\sum_{1}^{j} d_{i j}^{-2}} & \text { if } d_{i j} \leq D(k) \text { for } k=\{1 ; 2 ; 3\} \\ 0 & \text { if } d_{i j}>D(k)\end{cases}
$$

where $w_{i j}$ denotes the an element of the spatial weight matrix $W$ in row $i$ and column $j$. That is, $w_{i j}$ equals the inverse of distance squared, as long as the distance is below a critical threshold, otherwise it is zero. As the thresholds distance, we use quartiles $(k)$ of the overall distribution of great circle distances among all region pairs. The quartile values are as follows: $\{D(1)=660 ; D(2)=1090 ; D(3)=1594\}$. ${ }^{19}$ Some EU countries have regions that are overseas territories far away from the country's mainland. ${ }^{20}$ Including these regions would inflate the cut off distances for the quartiles. Furthermore, the impact of the nearest EU regions on these oversea territories might not be economically plausible. ${ }^{21}$ For this reason, we exclude all EU oversea territories from the spatial analysis.

We estimate a Spatial Durbin Model (SDM):

$$
\Delta \ln (\mathbf{y})=\rho\left(\mathbf{I}_{T} \otimes \mathbf{W}\right) \Delta \mathbf{y}+\mathbf{X} \beta+\left(\mathbf{I}_{T} \otimes \mathbf{W}\right) \mathbf{X} \theta+\mu+\mathbf{u}
$$

where $\Delta \mathbf{y}$ is $1 \times n t$ vector denoting the growth of output per capita, $\mathbf{X}$ is a $m \times n t$ matrix collecting the explanatory variables, $\mathbf{W}$ is the spatial weight matrix of size $n \times n$ and $\rho$ denotes the coefficient of the spatial lag, with $n, m$ and $t$ denoting the number of observations, number of explanatory variables, and years, respectively. The kronecker product of the the identity matrix $\mathbf{I}_{T}$ with the dimensions $t \times t$ accommodates $\mathbf{W}$ for a use in a panel regression. Additionally, the $\theta$ denotes the coefficient for the spatially lagged explanatory variables in the $\mathbf{X}$ matrix. The full spatial model is based on the first two lines of of the OLS model in (1), with the dummies for different country groups being omitted; instead, we add an interaction between the EU funds and institutional quality.

18 We also conduct regressions with a spatial weight matrix based on $k$ nearest neighbors, with $k=$ $\{5 ; 10 ; 15 ; 25 ; 50\}$. These results, which are available upon request, indicate that our model is robust to the choice of the spatial weight matrix.

19 We also use a spatial weight matrix based on a cut-off value the quartiles of great circle distances for each region specifically, what results in an equal number of non-zero values for each region. The difference in results is negligible.

20 The following NUTS 2 regions are overseas territories: Madeira, Azores, Canary Islands, Ceuta, Melilla, Guadeloupe, Martinique, French Guiana and Réunion.

21 As an example, consider the French oversea territories in the Indian Ocean such as Réunion. These are more likely to be economically influenced by mainland France rather than the nearest region, which is Cyprus. 
Note that in contrast to OLS or 2SLS, the partial derivatives of the SDM are more complex to interpret. A change in a variable affect the region itself as well as other regions, giving rise to direct and indirect effects. Let $\mathbf{S}$ be defined as:

$$
\mathbf{S}=\frac{\delta \Delta \ln (\mathbf{y})}{\delta \mathbf{x}_{\mathbf{i k}}}=\left(\mathbf{I}_{N T}-\rho \mathbf{I}_{T} \otimes \mathbf{W}\right)^{-1}\left(\mathbf{I}_{N T} \beta_{k}+\mathbf{I}_{T} \otimes \mathbf{W} \theta_{k}\right)
$$

where $x_{k}$ and $\beta_{k}$ represent the $k^{t h}$ column of the $\mathbf{X}$ and $\beta$ matrices respectively. The average direct effect is then given as $A D E=\frac{1}{n t} \operatorname{tr}(\mathbf{S})$, the average total effect is $A T E=$ $\frac{1}{n t} \iota^{\prime} \mathbf{S} \iota$ and the average indirect affect is then $A I E=A T E-A D E$. In other words, the $A D E$ is the average of the sum of all diagonal elements of $\mathbf{S}, A I E$ is the average of the sum of all off-diagonal elements of $\mathbf{S}$ and $A T E$ is the average of the sum of all elements of $\mathbf{S}$, with $\iota$ being a summation vector of ones. The convergence rate in the SDM has the following form:

$$
\lambda_{\text {spatial }}=-\frac{\ln \left(1+\ln y_{i j t-1}^{A T E}\right)}{t}
$$

The half-life of convergence remains $\frac{\ln (2)}{\lambda_{\text {spatial }}}$.

The preceding discussion evolves around estimating the impact of EU funds on regional growth. The result of such an analysis is an elasticity of the growth rate with respect to percentage changes in the ratio of EU funds to GDP. The downside of such analysis is that quantifying the impact of increasing regional aid on the level of output is not straightforward. Therefore, as an alternative, we estimate the additional output that could be attributed to spending one more euro of European funds. To get this perspective, we formulate a model based on aggregate variables:

$$
\begin{aligned}
\ln Y_{i j t}= & \beta_{0}+\beta_{1} \ln \left(Y_{i j t-1}\right)+\beta_{2} \ln \left(S_{i j t}\right)+\beta_{3} \ln \left(P_{i j t}\right)+\beta_{4} \text { wgipca }_{i t} \\
& +\gamma_{1} \ln \left(E U F_{i t}\right)+\mu_{j}+\tau_{t}+u_{i j t}
\end{aligned}
$$

where $Y$ is the aggregate output, $S$ stands for the gross fixed capital formation, $P$ is the population, and EUF is the total amount of EU Funds received. Furthermore, to allow for country-specific heterogeneity in the return to EU Funds invested, we estimate an extended version of the same model with country-specific elasticities aggregate output with respect to EU Funds:

$$
\begin{aligned}
\ln Y_{i j t}= & \beta_{1} \ln \left(Y_{i j t-1}\right)+\beta_{2} \ln \left(S_{i j t}\right)+\beta_{3} \ln \left(P_{i j t}\right)+\beta_{4} \text { wgipca }_{i t} \\
& +\sum_{i=1}^{28} \gamma_{i} \ln \left(E U F_{i t}\right) * D_{i}+\mu_{j}+\tau_{t}+u_{i j t}
\end{aligned}
$$

where $D_{i}$ represents a set of dummy variables denoting the individual member states.

This yields a set of elasticities of the impact of EU Funds on the level of each member state's aggregate output. Denoting the estimate of the elasticity of country $i$ 's output to its receipts from EU Funds as $\gamma_{i}$, we note that this elasticity can be expressed as follows:

$$
\gamma_{i}=\frac{\frac{\Delta Y_{i t}}{\Delta E U F_{i t}}}{\frac{y_{i t}}{E U F_{i t}}} .
$$

Rearranging this, we obtain the marginal effect of EU Funds on output:

$$
\frac{\Delta Y_{i t}}{\Delta E U F_{i t}}=\frac{\gamma_{i}}{\frac{E U F_{i t}}{Y_{i t}}} .
$$


Hence, the additional output that can be attributed to increasing EU Funds by 1 euro can be computed by dividing the estimated elasticity by the ratio of EU funds to output.

\section{Results}

\subsection{Cohesion Policy and Regional Output Growth}

Table 3 reports the results of estimating equation (1), on the effect of EU Funds on regional growth in the EU, by OLS. In the first column, we report the results of a standard Solow model (Mankiw et al., 1992; Islam, 1995). The coefficients of all variables are strongly significant and have the expected signs: negative for the lagged output per capita (consistent with the convergence effects, whereby more developed regions grow more slowly), positive for the investment rate (higher investment/savings rate implies a higher steady state and, in turn, faster growth rate when the region is below its steady-state level), and negative for the term entailing population growth (the dependent variable is the growth rate of output per capita, so that higher population growth implies that incremental increases in output need to be shared among larger number of individuals).

In the next four columns, we explore the effect of our variable of interest: transfers under the EU Cohesion Policy. In column (2), the ratio of EU Funds to GDP appears with a positive and strongly significant coefficient: the Cohesion-Policy spending boosts regional economic growth in the EU. In column (3), we add a measure of (nation-wide) institutional quality, which is also strongly significant and positive: regions in countries with good institutions grow more dynamically. Importantly, controlling for the quality of institutional environment does not diminish the positive effect of EU Funds; in fact, the estimated impact strengthens somewhat. Adding an interaction between institutional quality and EU Funds (column 4) changes little: the coefficients of EU Funds and institutions remain of the same sign and similar magnitude as before, while the interaction term appears insignificant. Hence, our results suggest that the effect of regional aid on growth is not conditional on good institutions. Finally, in column (5), we allow the effect of EU funds to vary across different groups of countries: GIPS (Greece, Ireland, Portugal and Spain), EU10 (the ten member states that joined the EU in 2004), and EU3 (Bulgaria, Romania and Croatia, the most recent entrants to the EU), with the remaining member states constituting the baseline against which these groups are compared. The GIPS countries used to be the main recipients of regional aid in the past, while the EU10 and EU3 are the primary beneficiaries of Cohesion Policy at present. Our results suggest that the positive effects of regional aid are observed mainly in regions in the new member states. However, somewhat surprisingly, the estimated group-specific coefficients are not very precisely estimated. This suggests that there is considerable heterogeneity also within these broad groups of countries. We return to this issue below, when we estimate country-specific effects.

As we argue above, there are good reasons to expect the effect of Cohesion Policy to be endogenous. If this is the case, the effects estimated in Table 3 would be biased. Therefore, in Table 4, we use the instrumental-variable approach to obtain endogeneity-robust estimates of the effect of EU Funds on regional growth. We use the presence of areas protected under the Natura 2000 program to construct instruments for the receipts of Cohesion Policy funds. We construct two alternative measures: the proportion of the region's area that is covered by Natura 2000 sites (areaprop), and the number of such sites (count). As ex- 
pected, both are strongly and positively correlated with the ratio of EU Funds to regional GDP: NUTS 2 regions with environmentally protected areas receive more funding than regions without environmentally protected areas. We use the proportion of protected area as our primary instrument, as we believe it is more informative than the mere number of protected sites. $^{22}$

In column (1) of Table 4, we report the results of the regression where the EU Funds to GDP ratio is instrumented by the proportion of the area covered by Natura 2000 sites. Column (2) reports the associated first-stage regression. The EU Funds have a robust and positive effect on growth. The coefficient estimate is approximately four times larger than that obtained with OLS, suggesting that endogeneity biases the estimated effects downwards. ${ }^{23}$ Adding institutional quality (columns 3-4) does not change this conclusion. Finally, in the last two columns we use both Natura 2000 instruments. This allows us to compute the Hansen J statistics (which cannot be computed when the endogenous variable is exactly identified). The Hansen $\mathrm{J}$ is insignificant: the instruments are thus valid. The high F statistics in columns (2), (4) and (6) confirm that the instrument(s) are also strong: the first-stage F-statistic is always greater than 100, well above the rule-of-thumb threshold of 10. We can therefore conclude that Cohesion Policy indeed boosts regional growth.

Finally, is it worth noting that the presence of Natura 2000 sites is positively correlated with the regional aid that regions receive. This holds both for the proportion of the region's area that is under environmental protection and the number of protected sites. As discussed in the Introduction, this positive correlation could either stem from the fact that Cohesion Policy supports projects that aim to protect the environment, or it could be driven by the additional technical requirements due to restrictions in areas with protected status.

\subsection{Inter-regional Spillovers of Cohesion Policy}

Table 5 reports the results of the SDM estimation of the effect of EU Funds on regional growth, which allows for inter-regional spillover effects of Cohesion Policy. Table 6 then summarizes these by reporting the direct, indirect and total effects. The test results in the bottom part of Table 5 indicate that the SDM is preferred not only over the OLS model, but also over the Spatial Error Model and the Spatial Autoregressive Model. The coefficient of spatial dependence, $\rho$, is significantly positive implying positive spillovers in GDP per capita growth rates. As a result of the positive indirect effect of output, however, the convergence rate in the SDM is lower than those implied by our OLS and 2SLS results. For the EU funds, the direct effect approaches zero and is insignificant. In contrast, the indirect effect is positive and statistically significant. The total effect is therefore also positive: regional aid to a region helps the surrounding regions more than the recipient region itself. The same can be said the investment rate: the direct effect is relatively small

\footnotetext{
${ }^{22}$ Some Natura 2000 sites are very small. The smallest protected area is Bradlo (SKUEV0402), a disused iron ore mine in Slovakia, with a surface area of 1 square meter, which serves as a nesting site for several species of bats. The next 26 sites (all located in Germany, mainly old churches and roofs of old buildings) each account for less than 20 square meters. The number of sites therefore could overestimate the extent of environmental protection in regions with many such small sites.

23 As we argue in the Introduction, this kind of bias could be driven by the fact that slowly-growing regions receive more regional aid because they remain eligible for funding earmarked for Less Developed Regions and/or Transitions Regions for longer. In contrast, dynamically-growing regions graduate from these classes of regions and thereby lose eligibility for the bulk of Cohesion Policy funding.
} 
but the spatial spillovers are positive and statistically significant, resulting in a statistically significant and positive total effect.

\subsection{Quantifying the Return to Cohesion Policy Spending}

So far, the analysis has been concerned with the effect of Cohesion Policy spending on regional economic growth. Our findings show that this effect is significantly positive: regional aid accelerates the regions' growth performance. The resulting elasticities, however, do not lend themselves to a straightforward quantitative assessment of the return on Cohesion Policy funds invested in the regions. Therefore, as the final step in our analysis, we estimate the relationship between aggregate GDP and the volume of EU Funds received by each region, as put forward by equations (7) and (8). This analysis allows us to quantify how much bang for the buck each euro of Cohesion Policy spending generates, as shown in equation (10).

Table 7 reports the results of the regressions with regional aggregate variables as given by equation (7). We again start by estimating a baseline regression, relating output to investment in physical capital and population size (column 1). Then, we add aggregate EU Funds (column 2), institutional quality (column 3) and the interaction of these two variables (column 4). In the last column, we allow the EU Fund effect to be different in the EU10, EU3 and GIPS. The EU Funds are always significantly correlated with regional economic activity. When we allow for differences between the groups of countries, the regional aid effect is insignificant for the baseline but strongly positive in the new member states: the interaction terms for the EU10 and EU3 are both significant and positive. In contrast, we observe a negative effect for the GIPS group: Greece, Ireland, Portugal and Spain. We suspect that this may be because of the relatively poor economic performance of these countries during the recent Global Financial Crisis and in its aftermath.

In the last four columns, we again instrument the Cohesion Policy receipts with the proportion of region's area protected by the Natura 2000 program (column 6, with the first stage reported in column 7) and the number of protected sites (columns 8-9). When estimating the aggregate relationship, the 2SLS coefficients tend to be similar (in size and significance level) to those obtained with OLS.

In the bottom part of Table 7, we compute the multiplier effects implied by the estimated elasticities and the EU Funds to GDP ratios, as given by equation (10). With the EUwide average EUF/Y ratio being 0.007 (so that the Cohesion Policy receipts on average amount to $0.7 \%$ of GDP) and with the output elasticity to regional aid being 0.0016 , the EU-wide regional multiplier is 0.24 . That is, for every $€ 1$ of EU Funds spent in the region, overall output increases by 24 cents. While this may seem as low, one needs to bear in mind that this is only the effect on the recipient region. Our analysis considers NUTS 2 regions, which are closely integrated into their national economies as well into the wider EU single market. One can therefore assume that $€ 1$ invested in the recipient region has further positive effects on output in other regions within the same country and also in other EU member states; indeed, our results based on estimating a spatial model of growth do suggest this. ${ }^{24}$

\footnotetext{
${ }^{24}$ Our estimate is consistent with the finding of Zawistowski et al. (2011) who conclude that each $€ 1$ of Cohesion Policy funds spent in the Visegrad Four countries and translates into 61 cents of additional exports from the EU15 countries.
} 
The regression in column (5) allows us to compute multipliers for country groups. Our calculation suggests that one euro of EU Funds increases output by 13 cents in the EU10 and by 26 cents in the EU3. In contrast, the effect in the GIPS countries is strongly negative, a fall in output by 52 cents. In the rest of the EU, the effect also negative but more moderate, at -21 cents. However, one should bear in mind that the effect for the remaining countries is based on an insignificant coefficient estimate, so that it should be taken with a grain of salt: statistically speaking, the effect can be either positive or negative.

Estimating equation (8) allows us to compute a separate multiplier for each member state; these constitute average effects across all regions within the same country. The country-specific regression estimates and multipliers are reported in Table 8 and Figure 4. These estimates further demonstrate the high degree of heterogeneity in the effect of Cohesion Policy across the EU. The multiplier ranges from -31 in Denmark to 6.7 in Luxembourg: that is, one euro of regional aid is associated with output falling by 31 euros in Denmark and rising by 6.7 euros in Luxembourg. It is important to note, however, that these values are obtained for small countries, which, being relatively rich, are not important beneficiaries of the EU Cohesion Policy. For the main recipient countries in Southern and Eastern Europe, the estimated multiplier effects are more modest in size.

A few general observations can be made. The multipliers tend to be negative in the countries hit by the Global Financial Crisis and the ensuing austerity measures: -0.61 (based on an insignificant coefficient) for Ireland, -0.67 for Spain, -.29 for Portugal, -0.20 (based on an insignificant coefficient) for Greece, and -2.2 for Italy. Among the new member states, which are at present the main beneficiaries of Cohesion Policy, the estimated multipliers tend to be of intermediate size. Specifically, the effect is insignificant for Bulgaria (0.05), Cyprus (-0.09) and Hungary (0.00), 0.06 in Estonia, 0.10 in Malta, 0.13 for Latvia, 0.15 in Poland and Slovenia, 0.19 in Lithuania, 0.23 in the Czech Republic, 0.42 in Slovakia, and 0.47 in Romania. ${ }^{25}$ Interestingly, the United Kingdom, whose decision to renounce its EU membership was in part motivated by concerns about its contribution to the EU budget being too high, records one of the highest multiplier effect: each $£ 1$ of EU Funds generates $£ 3.1$ of additional output in this country.

Further research should shed more light on the factors behind this heterogeneity in the effect of Cohesion Policy. Several explanations could be advanced. It is possible that the countries that have been EU members longer have learned how to utilize the EU Funds more effectively. This could explain why some of the old member states in Western and Northern Europe report relatively high multiplier effects. Another possibility is that these differences are driven by the sectoral break-down of regional aid in the recipient regions. Cohesion Policy finances projects in the areas of research and innovation, support for small and medium sized enterprises, environment, transport, employment, training, and public administration. The recipient countries/regions have different developmental needs, and the break-down of regional aid therefore varies from country to country. It is possible that the return on investment varies across these areas. Moreover, spending in some areas can yield a short-term return (which would be captured by an analysis such as ours), while funds spent on other areas may only produce a return in the medium to long term. Finally, the negative effects estimated for some of the Southern European countries are probably driven by the effects of the austerity measures implemented during and in the aftermath

${ }^{25}$ Croatia also appers with a sizeable negative multiplier, -3.3 . This country only became EU member in 2013 and therefore this estimate is based on only modest regional aid inflows. 
of the Global Financial Crisis rather than being attributable to Cohesion Policy.

\section{Conclusions}

This paper reports on the results of our quest to identify the effect of the EU Cohesion Policy on regional growth in the EU. Unlike most of the previous literature, we account for the likely endogeneity of EU Funds in regional economic performance, and for the potential presence of inter-regional spillovers in regional-aid impact.

To address endogeneity, we use the presence of environmentally protected areas under the EU Natura 2000 program as instruments for Cohesion Policy transfers. The presence of such areas is strongly and positively related with the amount of EU Funds that NUTS 2 regions receive. Our findings confirm that payments from European Funds significantly boost regional growth and the level of regional output alike. Hence, Cohesion Policy helps facilitate convergence and reduces differentials in regional development in the EU. When we control for endogeneity of Cohesion Policy, the estimated effects appear stronger than those obtained with OLS. Hence, endogeneity of regional aid biases the estimated effect downwards, which may help explain why many previous studies failed to identify a significant effect.

The results of estimating a spatial model of regional aid and growth confirm that interregional spillovers are important. In fact, our findings suggest that most of the impact of Cohesion Policy takes place in nearby regions rather than in the recipient region.

When we attempt to quantify the size of the regional aid effect, we find that on average $€ 1$ of EU Funds raises the output of the recipient region by 24 cents. While this estimate may seem low, it is important to bear in mind that it does not include the potential increased demand in other regions. Our spatial analysis indeed suggests that such spillovers are important: Cohesion Policy spending in one region can raise output in that region or it can be used to purchase goods and services from other regions.

There is, nevertheless, considerable heterogeneity across countries in the effectiveness of regional aid. The multiplier effects exceed unity in some Western and Northern old member states: Austria, Luxembourg, and somewhat surprisingly also in the United Kingdom. They are positive but less than one in most of the new member states: Lithuania, Latvia, Malta, Poland, Czech Republic, Slovakia and Romania. Finally, the countries hit especially adversely by the recent Global Financial Crisis - Ireland, Greece, Portugal, Spain and Italy - report negative multiplier effects. 


\section{References}

Arbia, G. (2006). Spatial econometrics: Statistical foundations and applications to regional convergence. Springer Science \& Business Media.

Bähr, C. (2008). How does sub-national autonomy affect the effectiveness of Structural Funds? Kyklos, 61(1):3-18.

Barro, R. J. (1974). Are government bonds net wealth? Journal of political economy, 82(6):1095-1117.

Barro, R. J. (1979). On the determination of the public debt. Journal of political Economy, 87(5, Part 1):940-971.

Becker, S. O., Egger, P. H., and Von Ehrlich, M. (2010). Going NUTS: The effect of EU Structural Funds on regional performance. Journal of Public Economics, 94(9-10):578590 .

Becker, S. O., Egger, P. H., and Von Ehrlich, M. (2012). Too much of a good thing? On the growth effects of the EU's regional policy. European Economic Review, 56(4):648-668.

Becker, S. O., Egger, P. H., and von Ehrlich, M. (2018). Effects of EU regional policy: 1989-2013. Regional Science and Urban Economics, 69:143-152.

Beugelsdijk, M. and Eijffinger, S. C. (2005). The effectiveness of structural policy in the European Union: An empirical analysis for the EU-15 in 1995-2001*. JCMS: Journal of Common Market Studies, 43(1):37-51.

Boldrin, M., Canova, F., Pischke, J.-S., and Puga, D. (2001). Inequality and convergence in Europe's regions: Reconsidering European regional policies. Economic policy, pages $207-253$.

Bradley, J., Morgenroth, E., Gács, J., and Untiedt, G. (2004). A study of the macroeconomic impact of the reform of EU Cohesion Policy. ESRI, Dublin, Ireland.

Bradley, J. and Untiedt, G. (2007). Do economic models tell us anything useful about Cohesion Policy impacts. Münster (GEFRA Working Paper: Juli 2007-Nr. 3).

Cappelen, A., Castellacci, F., Fagerberg, J., and Verspagen, B. (2003). The impact of EU regional support on growth and convergence in the European Union. JCMS: Journal of Common Market Studies, 41(4):621-644.

Cerqua, A. and Pellegrini, G. (2018). Are we spending too much to grow? The case of Structural Funds. Journal of Regional Science, 58(3):535-563.

Dall'Erba, S. and Le Gallo, J. (2008). Regional convergence and the impact of European Structural Funds over 1989-1999: A spatial econometric analysis. Papers in Regional Science, 87(2):219-244.

Dall'Erba, S., Le Gallo, J., et al. (2007). The impact of EU regional support on growth and employment. Czech Journal of Economics and Finance, 57(7):325-340.

Dall'erba, S. and Fang, F. (2017). A meta-analysis of the estimated impact of Structural Funds on regional growth. Regional Studies, 51.

Doucouliagos, H. and Paldam, M. (2009). The aid effectiveness literature: The sad results of 40 years of research. Journal of Economic Surveys, 23(3):433-461. 
Econometrics, C. (2016). European regional database.

Eggert, W., Von Ehrlich, M., Fenge, R., and König, G. (2007). Konvergenz-und Wachstumseffekte der europäischen Regionalpolitik in Deutschland. Perspektiven der Wirtschaftspolitik, 8(2):130-146.

Fagerberg, J. and Verspagen, B. (1996). Heading for divergence? Regional growth in Europe reconsidered. JCMS: Journal of Common Market Studies, 34(3):431-448.

Gantioler, S., Rayment, M., Ten Brink, P., McConville, A., Kettunen, M., and Bassi, S. (2014). The costs and socio-economic benefits associated with the Natura 2000 network. International Journal of Sustainable Society, 6(1-2):135-157.

Islam, N. (1995). Growth empirics: A panel data approach. The Quarterly Journal of Economics, pages 1127-1170.

Kaufmann, D., Kraay, A., and Mastruzzi, M. (2011). The Worldwide Governance Indicators: Methodology and analytical issues. Hague Journal on the Rule of Law, 3(02):220246.

Kopczewska, K., Kudła, J., and Walczyk, K. (2017). Strategy of spatial panel estimation: Spatial spillovers between taxation and economic growth. Applied Spatial Analysis and Policy, 10(1):77-102.

Le Gallo, J., Dall'Erba, S., and Guillain, R. (2011). The local versus global dilemma of the effects of Structural Funds. Growth and Change, 42(4):466-490.

Mankiw, N. G., Romer, D., and Weil, D. N. (1992). A contribution to the empirics of economic growth. The quarterly journal of economics, 107(2):407-437.

Marzinotto, B. (2012). The growth effects of eu cohesion policy: a meta-analysis. Technical report, Bruegel working paper.

Maynou, L., Saez, M., Kyriacou, A., and Bacaria, J. (2014). The impact of Structural and Cohesion Funds on Eurozone convergence, 1990-2010. Regional Studies, pages 1-13.

Mohl, P. and Hagen, T. (2010). Do EU Structural Funds promote regional growth? New evidence from various panel data approaches. Regional Science and Urban Economics, 40(5):353-365.

Mohl, P., Hagen, T., et al. (2008). Does EU Cohesion Policy promote growth? Evidence from regional data and alternative econometric approaches. Technical report, ZEW-Zentrum für Europäische Wirtschaftsforschung/Center for European Economic Research.

Pellegrini, G., Terribile, F., Tarola, O., Muccigrosso, T., and Busillo, F. (2013). Measuring the effects of European regional policy on economic growth: A regression discontinuity approach. Papers in Regional Science, 92(1):217-233.

Quah, D. T. (1996). Empirics for economic growth and convergence. European economic review, 40(6):1353-1375.

Radvansky, M., Lichner, I., and Miklosovic, T. (2015). Using regional Hermin model at NUTS3 level for CSF ex-post assessment in Slovakia. EcoMod2015 8466, EcoMod. 
Rodriguez-Pose, A. and Fratesi, U. (2004). Between development and social policies: The impact of European Structural Funds in Objective 1 regions. Regional Studies, 38(1):97113.

Rodríguez-Pose, A. and Garcilazo, E. (2015). Quality of government and the returns of investment: Examining the impact of cohesion expenditure in European regions. Regional Studies, 49(8):1274-1290.

Roemisch, R. (2017). Establishment of consolidated financial data 1989-2013. DirectorateGeneral for Regional and Urban Policy, European Commission.

Teorell, J., Dahlberg, S., Holmberg, S., Rothstein, B., Alvarado Pachon, N., and Svensson, R. (2018). The Quality of Government standard dataset, version Jan18. University of Gothenburg. The Quality of Government Institute.

Venables, A. and Gasiorek, M. (1999). The socio-economic impact of projects financed by the Cohesion Fund: A modeling approach. Luxembourg: European Commission.

Wostner, P. and Šlander, S. (2009). The effectiveness of EU Cohesion Policy revisited: are EU Funds really additional? European Policies Research Centre.

Zawistowski, J., Bartkiewicz, P., Cukrowska, E., Gębska, J., Regulski, A., Zub, M., Rosik, P., Szczygielski, K., Szpor, A., Kowal, P., Bukowski, M., and Antosiewicz, M. (2011). Evaluation of benefits to the EU-15 countries resulting from the implementation of Cohesion Policy in the Visegrad Group countries. Ministry of Regional Development, Department of Structural Policy Coordination, Warsaw. 


\section{Appendix}
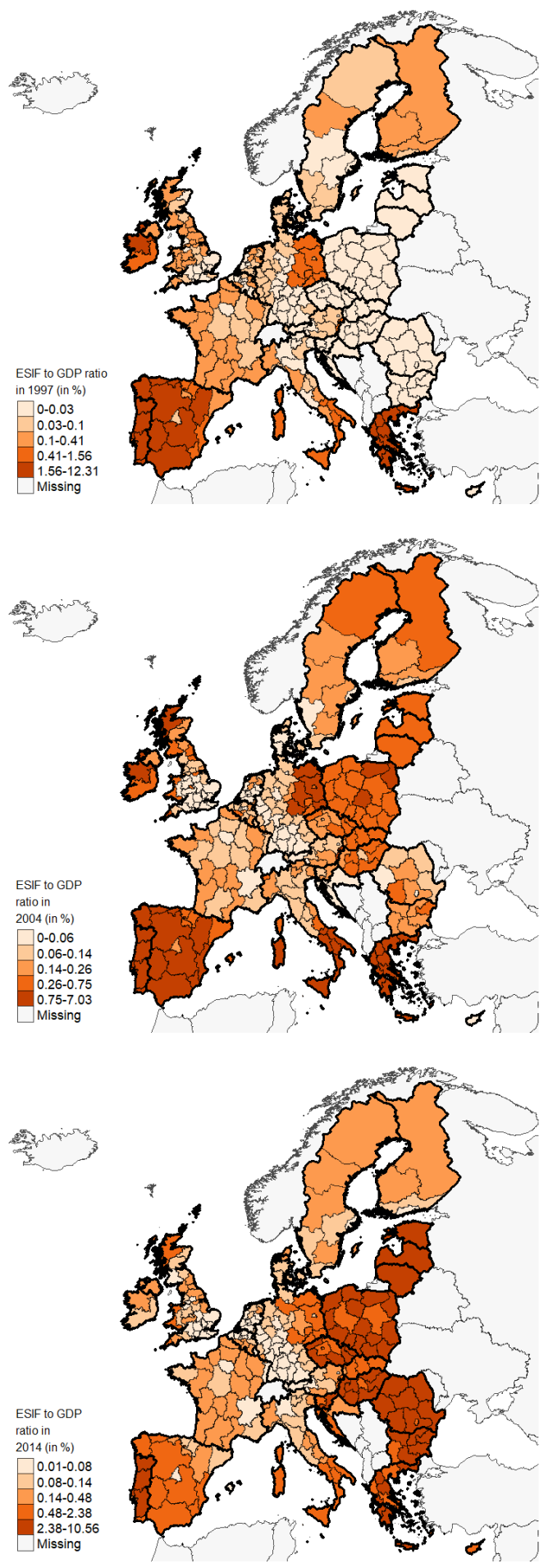

Figure 1: The ratio of approximate yearly structural funds to regional GDP in 1997, 2004 and 2014. Source: Own depiction based on data from Cambridge Econometrics Database and DG Regio. 

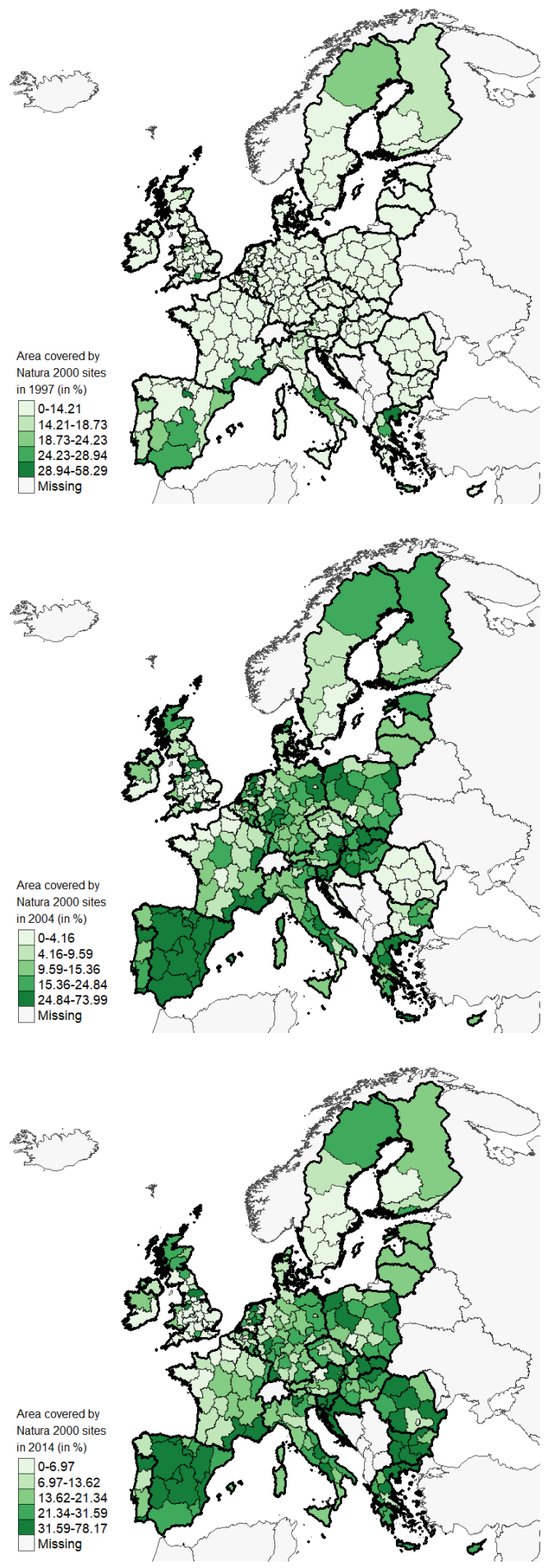

Figure 2: The ratio of the area of Natura 2000 sites to a region's total area.Source: Own depiction based on data from EEA and Eurostat. 


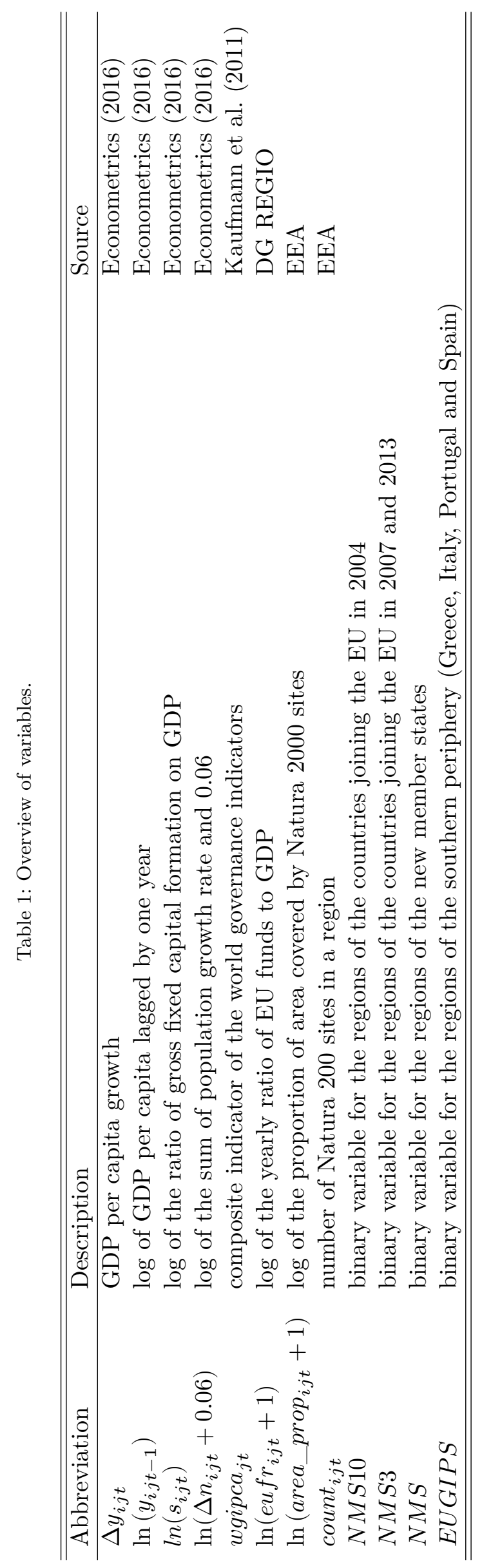


Table 2: Descriptive statistics

\begin{tabular}{lccccccc}
\hline \hline Statistic & $\mathrm{N}$ & Mean & St. Dev. & Min & Pctl(25) & Pctl(75) & Max \\
\hline$\Delta y_{i j t}$ & 4,896 & 0.016 & 0.037 & -0.153 & -0.003 & 0.034 & 0.432 \\
$\ln \left(y_{i j t-1}\right)$ & 4,896 & 9.804 & 0.697 & 7.368 & 9.566 & 10.235 & 11.501 \\
$\ln \left(\Delta n_{i j t}+0.06\right)$ & 4,896 & -2.777 & 0.151 & -7.142 & -2.832 & -2.711 & -2.068 \\
$\ln \left(s_{i j t}\right)$ & 4,896 & -1.533 & 0.227 & -2.922 & -1.665 & -1.408 & -0.415 \\
$\ln \left(\right.$ eufr $\left._{i j t}+1\right)$ & 4,896 & 0.007 & 0.013 & 0.000 & 0.001 & 0.007 & 0.130 \\
wgipca $_{\text {jt }}$ & 4,896 & 0.375 & 2.035 & -5.415 & -1.088 & 1.879 & 3.820 \\
$\ln \left(\right.$ area_prop $\left._{i j t}+1\right)$ & 4,896 & 0.134 & 0.119 & 0.000 & 0.035 & 0.204 & 0.578 \\
count $_{i j t}$ & 4,896 & 68.371 & 109.119 & 0 & 7 & 87 & 895 \\
\hline
\end{tabular}




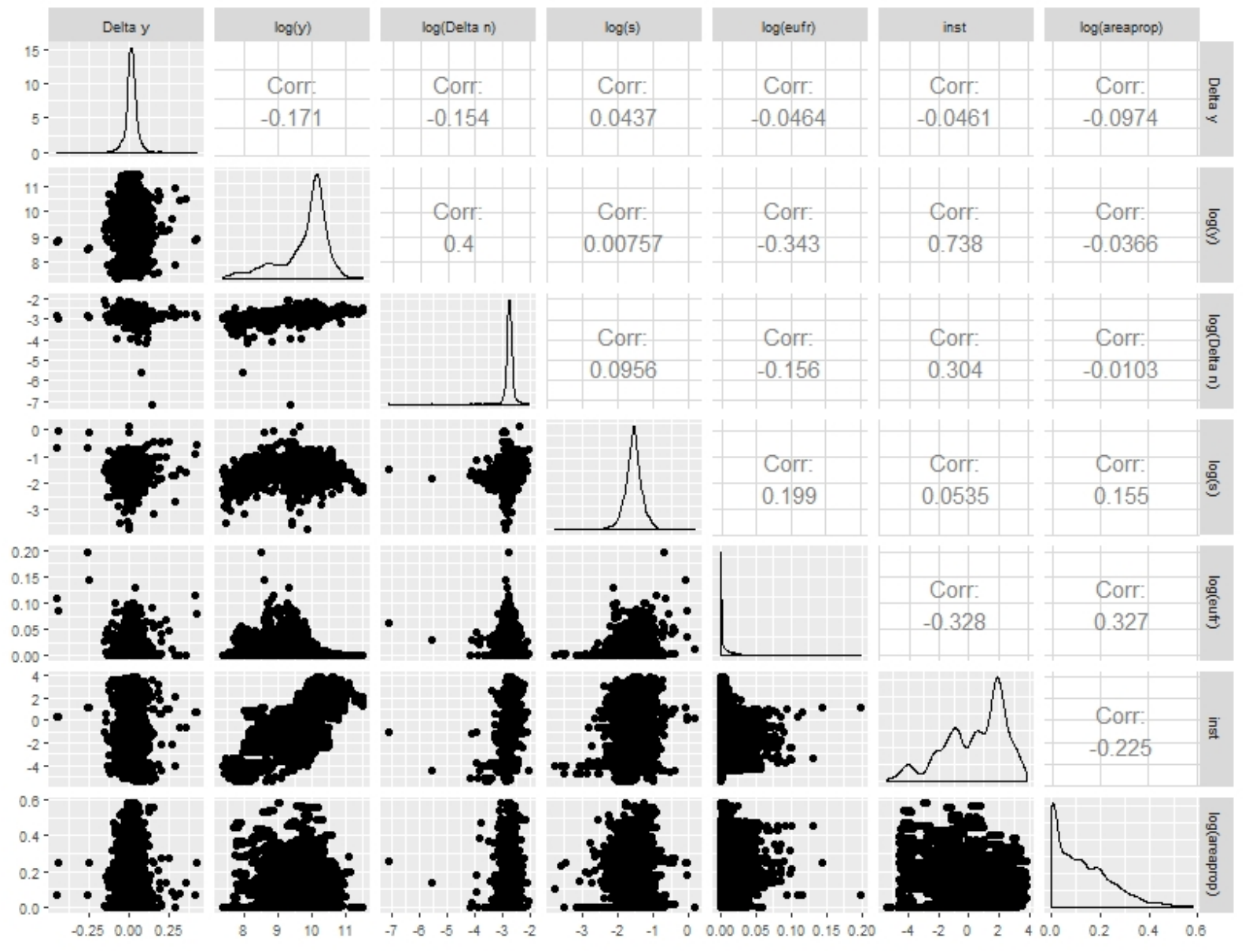

Figure 3: Correlogram of the computed variables. 
Table 3: European Funds and Regional Growth: OLS

\begin{tabular}{|c|c|c|c|c|c|}
\hline & $\begin{array}{c}(1) \\
\Delta \ln y_{i j t}\end{array}$ & $\begin{array}{c}(2) \\
\Delta \ln y_{i j t}\end{array}$ & $\begin{array}{c}(3) \\
\Delta \ln y_{i j t}\end{array}$ & $\begin{array}{c}(4) \\
\Delta \ln y_{i j t}\end{array}$ & $\begin{array}{c}(5) \\
\Delta \ln y_{i j t}\end{array}$ \\
\hline $\ln y_{i j t-1}$ & $\begin{array}{c}-0.095^{* * *} \\
(0.020)\end{array}$ & $\begin{array}{c}-0.107^{* * *} \\
(0.022)\end{array}$ & $\begin{array}{c}-0.137^{* * *} \\
(0.022)\end{array}$ & $\begin{array}{c}-0.135^{* * *} \\
(0.020)\end{array}$ & $\begin{array}{c}-0.147^{* * * *} \\
(0.022)\end{array}$ \\
\hline $\ln s_{i j t}$ & $\begin{array}{c}0.036^{* * *} \\
(0.009)\end{array}$ & $\begin{array}{c}0.033^{* * *} \\
(0.008)\end{array}$ & $\begin{array}{c}0.025^{* * *} \\
(0.008)\end{array}$ & $\begin{array}{c}0.026^{* * *} \\
(0.008)\end{array}$ & $\begin{array}{c}0.024^{* * *} \\
(0.008)\end{array}$ \\
\hline $\ln \left(n_{i j t}+g_{i j t}+\delta_{i j t}\right)$ & $\begin{array}{c}-0.036^{* * *} \\
(0.005)\end{array}$ & $\begin{array}{c}-0.035^{* * *} \\
(0.005)\end{array}$ & $\begin{array}{c}-0.036^{* * *} \\
(0.006)\end{array}$ & $\begin{array}{c}-0.036^{* * *} \\
(0.006)\end{array}$ & $\begin{array}{c}-0.035^{* * *} \\
(0.006)\end{array}$ \\
\hline $\ln \left(e u f r_{i j t}+1\right)$ & & $\begin{array}{c}0.395^{* * *} \\
(0.145)\end{array}$ & $\begin{array}{c}0.413^{* * *} \\
(0.123)\end{array}$ & $\begin{array}{c}0.517^{* * *} \\
(0.201)\end{array}$ & $\begin{array}{c}0.017 \\
(0.391)\end{array}$ \\
\hline wgipca $_{i t}$ & & & $\begin{array}{c}0.014^{* * *} \\
(0.002)\end{array}$ & $\begin{array}{c}0.013^{* * *} \\
(0.002)\end{array}$ & $\begin{array}{c}0.014^{* * *} \\
(0.002)\end{array}$ \\
\hline $\ln \left(e u f r_{i j t}+1\right)^{*}$ wgipca $_{i t}$ & & & & $\begin{array}{c}0.061 \\
(0.057)\end{array}$ & \\
\hline $\ln \left(e u f r_{i j t}+1\right)^{*} E U 10$ & & & & & $\begin{array}{c}0.543 \\
(0.413)\end{array}$ \\
\hline $\ln \left(e u f r_{i j t}+1\right)^{*} E U 3$ & & & & & $\begin{array}{l}0.775^{*} \\
(0.422)\end{array}$ \\
\hline $\ln \left(e u f r_{i j t}+1\right)^{*} G I P S$ & & & & & $\begin{array}{c}0.044 \\
(0.459)\end{array}$ \\
\hline$\lambda_{\text {non-spatial }}$ & $9.98 \%$ & $11.32 \%$ & $14.73 \%$ & $14.50 \%$ & $15.90 \%$ \\
\hline Half-life & 7.29 & 6.47 & 5.04 & 5.12 & 4.70 \\
\hline Observations & 4,896 & 4,896 & 4,896 & 4,896 & 4,896 \\
\hline $\mathrm{R}^{2}$ & 0.358 & 0.364 & 0.387 & 0.388 & 0.390 \\
\hline F-statistic & $150.798^{* * *}$ & $125.63^{* * *}$ & $138.52^{* * *}$ & $116.15^{* * *}$ & $89.39^{* * *}$ \\
\hline Regional FEs & Yes & Yes & Yes & Yes & Yes \\
\hline Time FEs & Yes & Yes & Yes & Yes & Yes \\
\hline
\end{tabular}

Notes: Standard errors in parentheses. Significance: ${ }^{*} \mathrm{p}<0.1 ;{ }^{* *} \mathrm{p}<0.05 ;{ }^{* * *} \mathrm{p}<0.01$. 


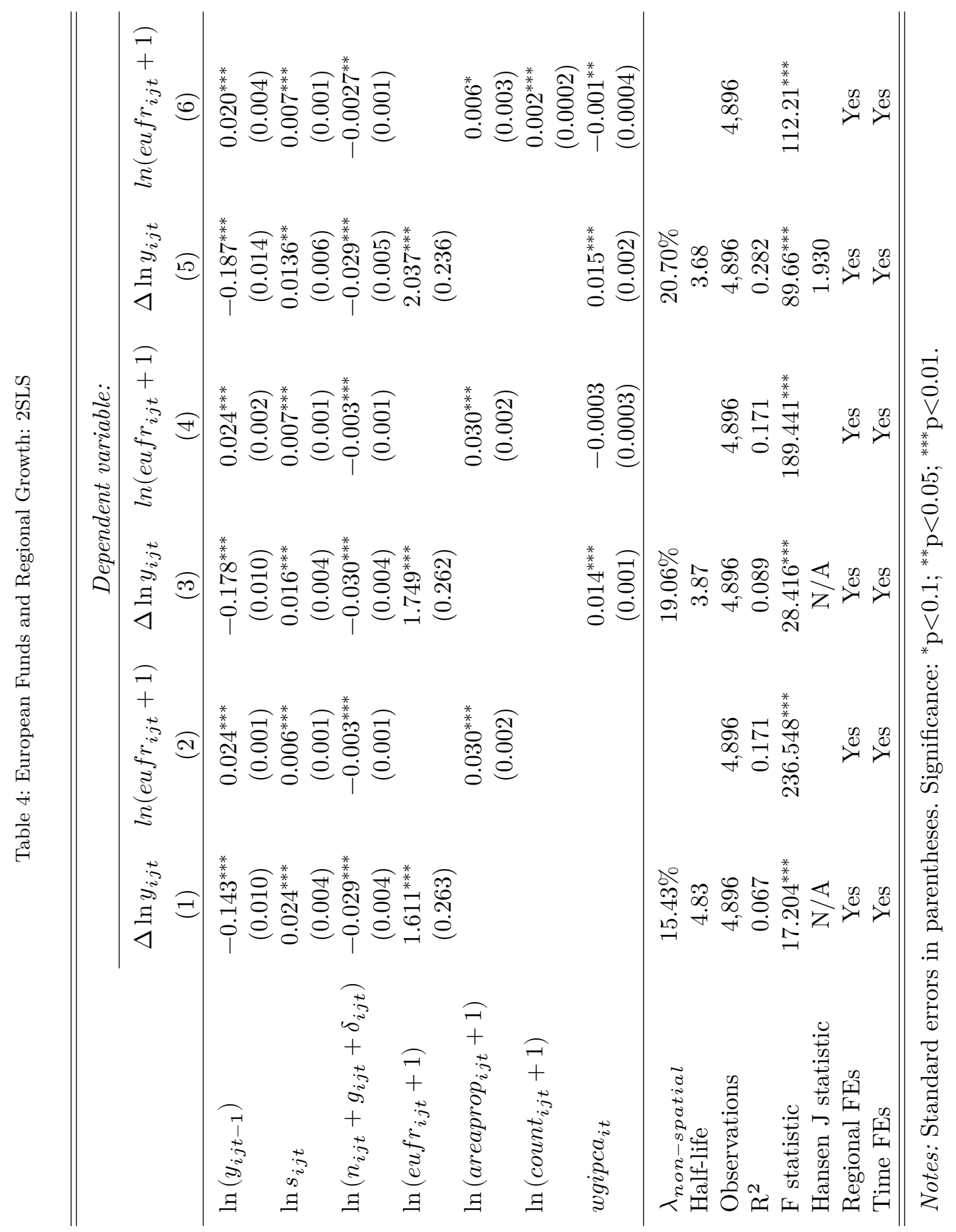


Table 5: Cohesion Policy and Inter-regional Spillovers: SDM

\begin{tabular}{|c|c|c|c|}
\hline & $\begin{array}{c}(1) \\
\Delta \ln y_{i j t} \\
\mathrm{D}(1)\end{array}$ & $\begin{array}{c}(2) \\
\Delta \ln y_{i j t} \\
\mathrm{D}(2)\end{array}$ & $\begin{array}{c}(3) \\
\Delta \ln y_{i j t} \\
\mathrm{D}(3)\end{array}$ \\
\hline$\rho$ & $\begin{array}{l}0.7398^{* * *} \\
(0.0134)\end{array}$ & $\begin{array}{c}0.7760^{* * *} \\
(0.0140)\end{array}$ & $\begin{array}{l}0.7948^{* * *} \\
(0.0143)\end{array}$ \\
\hline $\ln \left(y_{i j t-1}\right)$ & $\begin{array}{c}-0.1612^{* * *} \\
(0.0079)\end{array}$ & $\begin{array}{c}-0.1506^{* * *} \\
(0.0077)\end{array}$ & $\begin{array}{c}-0.1452^{* * *} \\
(0.0076)\end{array}$ \\
\hline $\ln \left(s_{i j t}\right)$ & $\begin{array}{c}0.0027 \\
(0.0031)\end{array}$ & $\begin{array}{c}0.0035 \\
(0.0031)\end{array}$ & $\begin{array}{c}0.0042 \\
(0.0031)\end{array}$ \\
\hline $\ln \left(n_{i j t}+g+\delta\right)$ & $\begin{array}{c}-0.0331^{* * *} \\
(0.0034)\end{array}$ & $\begin{array}{c}-0.0342^{* * *} \\
(0.0034)\end{array}$ & $\begin{array}{c}-0.0349^{* * *} \\
(0.0034)\end{array}$ \\
\hline wgipca $_{i t}$ & $\begin{array}{c}0.0117^{* * *} \\
(0.0016)\end{array}$ & $\begin{array}{c}0.0104^{* * *} \\
(0.0016)\end{array}$ & $\begin{array}{c}0.0097^{* * *} \\
(0.0016)\end{array}$ \\
\hline $\ln \left(e u f r_{i j t}+1\right)$ & $\begin{array}{l}-0.0053 \\
(0.1060)\end{array}$ & $\begin{array}{l}-0.0002 \\
(0.1040)\end{array}$ & $\begin{array}{l}-0.0013 \\
(0.1039)\end{array}$ \\
\hline $\ln \left(e u f r_{i j t}+1\right) * w_{g i p c a} i t$ & $\begin{array}{l}-0.0189 \\
(0.0426)\end{array}$ & $\begin{array}{l}-0.0555 \\
(0.0410)\end{array}$ & $\begin{array}{l}-0.0763 \\
(0.0407)\end{array}$ \\
\hline $\mathbf{W} * \ln \left(y_{i j t-1}\right)$ & $\begin{array}{c}0.1315^{* * *} \\
(0.0094)\end{array}$ & $\begin{array}{c}0.1245^{* * *} \\
(0.0094)\end{array}$ & $\begin{array}{c}0.1211^{* * *} \\
(0.0095)\end{array}$ \\
\hline $\mathbf{W} * \ln \left(s_{i j t}\right)$ & $\begin{array}{c}0.0219^{* * *} \\
(0.0055)\end{array}$ & $\begin{array}{c}0.0229^{* * *} \\
(0.0060)\end{array}$ & $\begin{array}{c}0.0241^{* * *} \\
(0.0064)\end{array}$ \\
\hline $\mathbf{W} * \ln \left(n_{i j t}+\delta+g\right)$ & $\begin{array}{c}0.0339^{* * *} \\
(0.0070)\end{array}$ & $\begin{array}{c}0.0359^{* * *} \\
(0.0080)\end{array}$ & $\begin{array}{c}0.0395^{* * *} \\
(0.0087)\end{array}$ \\
\hline $\mathbf{W} * \ln \left(w g i p c a_{i t}\right)$ & $\begin{array}{l}-0.0098^{* * *} \\
(0.0024)\end{array}$ & $\begin{array}{c}-0.0082^{* *} \\
(0.0027)\end{array}$ & $\begin{array}{l}-0.0067^{*} \\
(0.0030)\end{array}$ \\
\hline $\mathbf{W} * \ln \left(e u f r_{i j t}+1\right)$ & $\begin{array}{c}0.2987 \\
(0.1790)\end{array}$ & $\begin{array}{c}0.3487 \\
(0.2057)\end{array}$ & $\begin{array}{c}0.3799 \\
(0.2220)\end{array}$ \\
\hline $\mathbf{W} * \ln \left(e u f r_{i j t}+1\right) * w g i p c a_{i t}$ & $\begin{array}{c}0.0782 \\
(0.0631)\end{array}$ & $\begin{array}{c}0.1325 \\
(0.0704)\end{array}$ & $\begin{array}{l}0.1710^{*} \\
(0.0757)\end{array}$ \\
\hline$\lambda_{\text {spatial }}$ & $12.394 \%$ & $12.257 \%$ & $12.394 \%$ \\
\hline Half-life & 5.597 & 5.655 & 5.592 \\
\hline Observations & 4734 & 4734 & 4734 \\
\hline Log-likelihood & 10715.9469 & 10694.9388 & 10683.8882 \\
\hline$A I C$ & -21379.9 & -21337.9 & -21315.8 \\
\hline$B I C$ & -21211.9 & -21169.9 & -21147.8 \\
\hline Coefficient test $\theta=0\left(\chi^{2}\right)$ & $295.74^{* * *}$ & $266.85^{* * *}$ & $255.81^{* * *}$ \\
\hline Coefficient test $\theta=-\beta \rho\left(\chi^{2}\right)$ & $61.18^{* * *}$ & $53.07^{* * *}$ & $53.36^{* * *}$ \\
\hline Regional FEs & Yes & Yes & Yes \\
\hline Time FEs & No & No & No \\
\hline
\end{tabular}

Notes: Standard errors in parentheses. Significance: ${ }^{*} \mathrm{p}<0.1 ;{ }^{* *} \mathrm{p}<0.05 ;{ }^{* * *} \mathrm{p}<0.01$. 
Table 6: Cohesion Policy and Inter-regional Spillovers - Direct, Indirect and Total Effects

\begin{tabular}{|c|c|c|c|}
\hline & $\begin{array}{c}(1) \\
\Delta \ln y_{i j t} \\
\mathrm{D}(1)\end{array}$ & $\begin{array}{c}(2) \\
\Delta \ln y_{i j t} \\
\mathrm{D}(2)\end{array}$ & $\begin{array}{c}(3) \\
\Delta \ln y_{i j t} \\
\mathrm{D}(3)\end{array}$ \\
\hline \multicolumn{4}{|l|}{ Average Direct Effects } \\
\hline $\ln \left(y_{i j t-1}\right)$ & $\begin{array}{l}-0.159^{* * *} \\
(0.00791)\end{array}$ & $\begin{array}{l}-0.149^{* * *} \\
(0.00777)\end{array}$ & $\begin{array}{l}-0.144^{* * *} \\
(0.00766)\end{array}$ \\
\hline $\ln \left(s_{i j t}\right)$ & $\begin{array}{l}0.00600^{*} \\
(0.00297)\end{array}$ & $\begin{array}{c}0.00668^{*} \\
(0.00297)\end{array}$ & $\begin{array}{l}0.00745^{*} \\
(0.00298)\end{array}$ \\
\hline $\ln \left(n_{i j t}+g+\delta\right)$ & $\begin{array}{c}-0.0314^{* * *} \\
(0.00333)\end{array}$ & $\begin{array}{c}-0.0326^{* * *} \\
(0.00333)\end{array}$ & $\begin{array}{c}-0.0330^{* * *} \\
(0.00332)\end{array}$ \\
\hline wgipca $_{i t}$ & $\begin{array}{l}0.0115^{* * *} \\
(0.00153)\end{array}$ & $\begin{array}{l}0.0104^{* * *} \\
(0.00150)\end{array}$ & $\begin{array}{c}0.00980^{* * *} \\
(0.00151)\end{array}$ \\
\hline $\ln \left(e u f r_{i j t}+1\right)$ & $\begin{array}{c}0.0380 \\
(0.0999)\end{array}$ & $\begin{array}{c}0.0460 \\
(0.0972)\end{array}$ & $\begin{array}{c}0.0460 \\
(0.0967)\end{array}$ \\
\hline $\ln \left(e u f r_{i j t}+1\right) * w_{g i p c a} i t$ & $\begin{array}{r}-0.00777 \\
(0.0400)\end{array}$ & $\begin{array}{l}-0.0421 \\
(0.0385)\end{array}$ & $\begin{array}{l}-0.0610 \\
(0.0381)\end{array}$ \\
\hline \multicolumn{4}{|l|}{ Average Indirect Effects } \\
\hline $\ln \left(y_{i j t-1}\right)$ & $\begin{array}{c}0.0456^{*} \\
(0.0203)\end{array}$ & $\begin{array}{c}0.0339 \\
(0.0250)\end{array}$ & $\begin{array}{c}0.0277 \\
(0.0285)\end{array}$ \\
\hline $\ln \left(s_{i j t}\right)$ & $\begin{array}{c}0.0879^{* * *} \\
(0.0160)\end{array}$ & $\begin{array}{l}0.110^{* * *} \\
(0.0207)\end{array}$ & $\begin{array}{l}0.130^{* * *} \\
(0.0244)\end{array}$ \\
\hline $\ln \left(n_{i j t}+g+\delta\right)$ & $\begin{array}{c}0.0371 \\
(0.0237)\end{array}$ & $\begin{array}{c}0.0433 \\
(0.0319)\end{array}$ & $\begin{array}{c}0.0594 \\
(0.0381)\end{array}$ \\
\hline wgipca $_{i t}$ & $\begin{array}{l}-0.00397 \\
(0.00585)\end{array}$ & $\begin{array}{r}-0.000206 \\
(0.00818)\end{array}$ & $\begin{array}{c}0.00510 \\
(0.00994)\end{array}$ \\
\hline $\ln \left(e u f r_{i j t}+1\right)$ & $\begin{array}{c}1.064^{*} \\
(0.522)\end{array}$ & $\begin{array}{c}1.475^{*} \\
(0.726)\end{array}$ & $\begin{array}{c}1.757^{*} \\
(0.867)\end{array}$ \\
\hline $\ln \left(e u f r_{i j t}+1\right) *$ wgipca $_{i t}$ & $\begin{array}{c}0.233 \\
(0.170) \\
\end{array}$ & $\begin{array}{c}0.381 \\
(0.235)\end{array}$ & $\begin{array}{c}0.517 \\
(0.281) \\
\end{array}$ \\
\hline Average Total Effects & & & \\
\hline $\ln \left(y_{i j t-1}\right)$ & $\begin{array}{c}-0.114^{* * *} \\
(0.0203)\end{array}$ & $\begin{array}{c}-0.115^{* * *} \\
(0.0253)\end{array}$ & $\begin{array}{c}-0.117^{* * *} \\
(0.0290)\end{array}$ \\
\hline $\ln \left(s_{i j t}\right)$ & $\begin{array}{c}0.0939^{* * *} \\
(0.0164)\end{array}$ & $\begin{array}{l}0.117^{* * *} \\
(0.0211)\end{array}$ & $\begin{array}{l}0.137^{* * *} \\
(0.0247)\end{array}$ \\
\hline $\ln \left(n_{i j t}+g+\delta\right)$ & $\begin{array}{c}0.00574 \\
(0.0247)\end{array}$ & $\begin{array}{c}0.0107 \\
(0.0328)\end{array}$ & $\begin{array}{c}0.0264 \\
(0.0389)\end{array}$ \\
\hline wgipca $_{i t}$ & $\begin{array}{c}0.00753 \\
(0.00557)\end{array}$ & $\begin{array}{c}0.0102 \\
(0.00780)\end{array}$ & $\begin{array}{c}0.0149 \\
(0.00948)\end{array}$ \\
\hline $\ln \left(e u f r_{i j t}+1\right)$ & $\begin{array}{c}1.102^{*} \\
(0.529)\end{array}$ & $\begin{array}{c}1.521^{*} \\
(0.730)\end{array}$ & $\begin{array}{c}1.803^{*} \\
(0.869)\end{array}$ \\
\hline $\ln \left(e u f r_{i j t}+1\right) * w_{g i p c a} i t$ & $\begin{array}{c}0.226 \\
(0.171)\end{array}$ & $\begin{array}{c}0.339 \\
(0.234)\end{array}$ & $\begin{array}{c}0.456 \\
(0.280)\end{array}$ \\
\hline
\end{tabular}




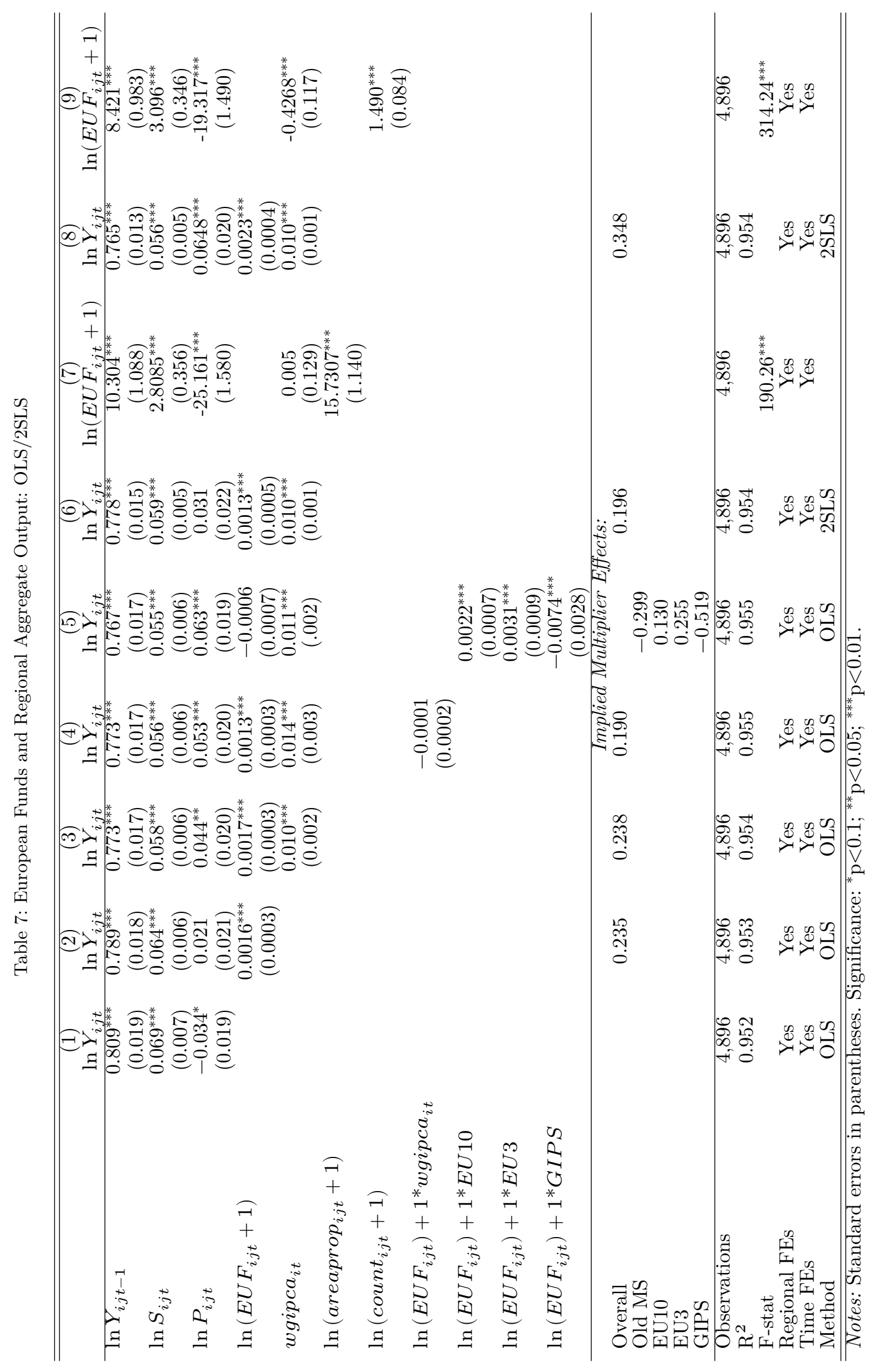


Table 8: European Funds and Regional Aggregate Output: Country-specific Effects

\begin{tabular}{|c|c|c|c|c|}
\hline & elasticity & $\begin{array}{l}\text { Depender } \\
\text { st.dev. }\end{array}$ & $\begin{array}{l}\text { variable } \\
\text { euf } / \mathrm{y}\end{array}$ & ${ }^{j t}$ multiplier \\
\hline $\ln Y_{i j t-1}$ & $0.7544^{* * *}$ & $(0.010)$ & & \\
\hline $\ln S_{i j t}$ & $0.0733^{* * *}$ & $(0.0054)$ & & \\
\hline $\ln P_{i j t}$ & $0.8405^{* * *}$ & $(0.0163)$ & & \\
\hline wgipca $_{i t}$ & $0.0063^{* * *}$ & $(0.0014)$ & & \\
\hline $\ln \left(E U F_{i t}+1\right) * a t$ & $0.0047^{* * *}$ & $(0.0016)$ & 0.0021 & 2.2838 \\
\hline $\ln \left(E U F_{i t}+1\right) * b e$ & 0.0003 & $(0.0008)$ & 0.0011 & 0.2985 \\
\hline $\ln \left(E U F_{i t}+1\right) * b g$ & 0.0006 & $(0.0012)$ & 0.0123 & 0.0501 \\
\hline $\ln \left(E U F_{i t}+1\right) * c y$ & -0.0002 & $(0.0001)$ & 0.0022 & -0.0875 \\
\hline $\ln \left(E U F_{i t}+1\right) * c z$ & $0.0019^{* * *}$ & $(0.0002)$ & 0.0086 & 0.2256 \\
\hline $\ln \left(E U F_{i t}+1\right) * d e$ & 0.0005 & $(0.0018)$ & 0.0023 & 0.2405 \\
\hline $\ln \left(E U F_{i t}+1\right) * d k$ & $-0.0143^{* * *}$ & $(0.0021)$ & 0.0005 & -31.6278 \\
\hline $\ln \left(E U F_{i t}+1\right) * e e$ & $0.0010^{* * *}$ & $(0.0003)$ & 0.0149 & 0.0642 \\
\hline $\ln \left(E U F_{i t}+1\right) * e l$ & -0.0054 & $(0.0045)$ & 0.0276 & -0.1970 \\
\hline $\ln \left(E U F_{i t}+1\right) * e s$ & $-0.0079^{* * *}$ & $(0.0014)$ & 0.0119 & -0.6685 \\
\hline $\ln \left(E U F_{i t}+1\right) * f i$ & -0.0081 & $(0.0091)$ & 0.0022 & -3.6294 \\
\hline $\ln \left(E U F_{i t}+1\right) * f r$ & $-0.0127^{* * *}$ & $(0.0030)$ & 0.0032 & -3.9850 \\
\hline $\ln \left(E U F_{i t}+1\right) * h r$ & $-0.0018^{* * *}$ & $(0.0005)$ & 0.0005 & -3.3224 \\
\hline $\ln \left(E U F_{i t}+1\right) * h u$ & 0.0001 & $(0.0006)$ & 0.0192 & 0.0044 \\
\hline $\ln \left(E U F_{i t}+1\right) * i e$ & -0.0041 & $(0.0056)$ & 0.0067 & -0.6094 \\
\hline $\ln \left(E U F_{i t}+1\right) * i t$ & $-0.0092^{*}$ & $(0.0054)$ & 0.0042 & -2.2110 \\
\hline $\ln \left(E U F_{i t}+1\right) * l t$ & $0.0031^{* * *}$ & $(0.0003)$ & 0.0166 & 0.1886 \\
\hline $\ln \left(E U F_{i t}+1\right) * l u$ & $0.0026^{* * *}$ & $(0.0009)$ & 0.0004 & 6.7068 \\
\hline $\ln \left(E U F_{i t}+1\right) * l v$ & $0.0020^{* * *}$ & $(0.0003)$ & 0.0153 & 0.1334 \\
\hline $\ln \left(E U F_{i t}+1\right) * m t$ & $0.0005^{* * *}$ & $(0.0001)$ & 0.0057 & 0.0958 \\
\hline $\ln \left(E U F_{i t}+1\right) * n l$ & 0.0019 & $(0.0022)$ & 0.0009 & 2.1692 \\
\hline $\ln \left(E U F_{i t}+1\right) * p l$ & $0.0021^{* * *}$ & $(0.0003)$ & 0.0143 & 0.1491 \\
\hline $\ln \left(E U F_{i t}+1\right) * p t$ & $-0.0103^{* * *}$ & $(0.0028)$ & 0.0354 & -0.2916 \\
\hline $\ln \left(E U F_{i t}+1\right) * r o$ & $0.0039^{* * *}$ & $(0.0004)$ & 0.0084 & 0.4682 \\
\hline $\ln \left(E U F_{i t}+1\right) * s e$ & 0.0025 & $(0.0026)$ & 0.0014 & 1.8018 \\
\hline $\ln \left(E U F_{i t}+1\right) * s i$ & $0.0013^{* * *}$ & $(0.0003)$ & 0.0072 & 0.1850 \\
\hline $\ln \left(E U F_{i t}+1\right) * s k$ & $0.0038^{* * *}$ & $(0.0004)$ & 0.0090 & 0.4209 \\
\hline $\ln \left(E U F_{i t}+1\right) * u k$ & $0.0045^{* * *}$ & $(0.0012)$ & 0.0014 & 3.1079 \\
\hline Observations & 4,896 & & & \\
\hline $\mathrm{R}^{2}$ & 0.957 & & & \\
\hline Regional FEs & Yes & & & \\
\hline Time FEs & Yes & & & \\
\hline
\end{tabular}




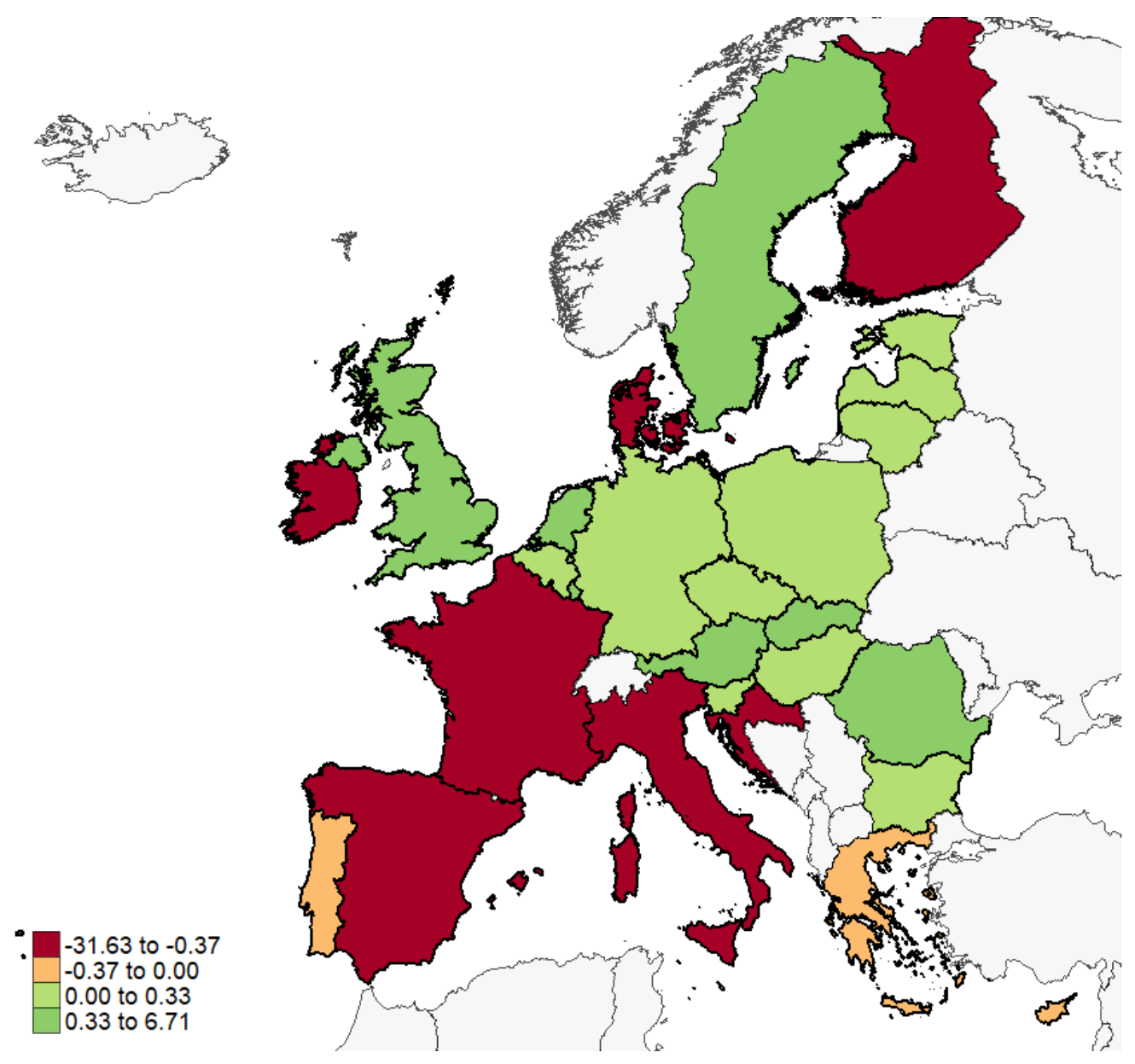

Figure 4: Multiplier of the impact of EU funds on GDP. 